\title{
DEL ENEMIGO POLÍTICO AL ENEMIGO EN LA NECROPOLÍTICA
}

\author{
FROM THE POLITICAL ENEMY TO THE ENEMY IN THE \\ NECROPOLITICS
}

\author{
Dra. Laura Álvarez Garro \\ lauraalvarezgarro@gmail.com
}

Costarricense. Psicoanalista. Doctora en Humanidades con énfasis en Filosofía Moral y Política por parte de la Universidad Autónoma Metropolitana, Sede Iztapalapa (UAM-I), Máster en Ciencias Sociales por parte de la Facultad Latinoamericana de Ciencias Sociales, Sede México (FLACSO-Mx), Licenciada en Psicología por parte de la Universidad de Costa Rica. Docente en el Doctorado en Estudios de la Sociedad y Cultura (DESC), en el Posgrado en Psicología (PPP), Posgrado en Filosofía, y Escuela de Filosofía. Investigadora en el Instituto de Investigaciones Filosóficas (INIF) y en el Centro de Investigación y Estudios Políticos (CIEP), todos de la Universidad de Costa Rica. Entre sus últimas publicaciones se encuentran "La "ideología costarricense" y el espectro de la "ideología extranjera” (1950-1959)" (2019); " Una "nueva armonía”: antagonismos políticos y conceptos-guía en la Costa Rica de 1950 a 1969” (2018); y “Democracia y sus contraconceptos durante la década de 1950-1959 en Costa Rica” (2018).

Recibido 30/10/2018 - Aceptado 01/04/2019

\section{RESUMEN}

Este artículo gira alrededor del concepto de enemigo, tomando como referente el trabajo de Carl Schmitt, en conjunción con aportes de Sigmund Freud y Jacques Lacan. El objetivo de este artículo es contrastar la propuesta de Schmitt con los aportes de Freud y Lacan, con la pretensión de solventar problemas de carácter teórico y práctico. Luego, se discute si la propuesta de Achille Mbembe sugiere una transformación en la idea de enemistad, o si es un agudizamiento de condiciones previas; analizando a profundidad si el enemigo en la necropolítica corresponde al planteamiento del enemigo absoluto en Schmitt. Finalmente, se examina cuáles son las condiciones políticas contemporáneas que han propiciado un aumento en los escenarios de necropoder.

Palabras clave: enemigo, comunidad política, identificación, psicoanálisis, realismo político, necropolítica. 


\section{ABSTRACT}

This article focuses around the concept of the enemy, taking as a reference the work of Carl Schmitt, with the contributions of Sigmund Freud and Jacques Lacan. The objective of this article is to contrast the Schmitt proposal with the contributions of Freud and Lacan, with the intention of solving theoretical and practical problems. Then, it is debated whether Achille Mbembe's proposal suggests a transformation in the idea of enmity, or if it is a sharpening of preconditions; analyzing in depth if the enemy in the necropolitics corresponds to the approach of the absolute enemy in Schmitt. Finally, we examine what are the contemporary political conditions that have led to an increase in necropower scenarios.

Key words: Enmity, political community, identification, psychoanalysis, political realism, necropolitics.

\section{INTRODUCCIÓN}

La coyuntura política y social que enmarca la escritura de este ensayo no es para nada alentadora. El horizonte de un futuro, en el cual las posibilidades de alcanzar una vida digna sean reales, parece alejarse una vez más. En una suerte de ironía histórica, estamos asistiendo a un retorno de discursos con claros tintes fascistas y totalitarios, a pesar de que se había creído que estos solamente seguían existiendo marginalmente. Las expectativas que se le depositaron a la democracia liberal-procedimental y al capitalismo han mostrado ser excesivas: no hubo un fin de la historia. Al contrario, la democracia liberal-procedimental ha fracasado en su tarea de contener y regular el conflicto; mientras que el capitalismo, en su forma contemporánea neoliberal, ha incrementado de manera escandalosa la desigualdad socioeconómica.

Es evidente que esta crítica a las falencias propias de las democracias liberales-procedimentales no es novedosa, por lo que antes que reeditar lo ya dicho en múltiples lugares (Álvarez, 2013; Laclau, 2005; Lefort, 1988, 1990; Rancière, 2006, 2007; Žižek, 2002, entre otros), lo que interesa mostrar en este artículo, es cómo esta coyuntura y sus efectos desafían la premisa sostenida por las corrientes de pensamiento político disociativas, que reconocen en el antagonismo y en el conflicto una condición necesaria para el establecimiento de comunidades políticas, y por ende, la condición del enemigo como exterior constitutivo. En ese sentido, la reflexión se dirige a discutir qué pasa cuando grupos humanos parecen estar más allá de lo político y son degradados a través del uso de categorías morales o de otros tipos, convertidas en el horror humano que no solo hay que rechazar, sino que hay que aniquilar definitivamente (Schmitt, 2009a, p. 66). 
Este pasaje pone en tensión el carácter del antagonismo, ya que la cuestión obliga a replantear dónde estaría el límite, en qué punto pasa de ser el conflicto la condición de posibilidad para la comunidad a la forma bajo la cual se legitima la exterminación del otro. El aumento de la defensa de las identidades, que ha llevado a una exacerbación de los nacionalismos y su concomitante xenofobia y desprecio por la diferencia, nos impone una tarea reflexiva y política de importancia radical.

Por tanto, este ensayo se dirige a analizar estos escenarios limítrofes, mismos que ya han sido planteados por Schmitt (1966, pp. 111, 123-129; 2009a, pp. 58-59, 65$66,83-84,106 ; 2009 b, 133-134$ ) y por Derrida (1998, pp. 94-95; 176). El primero advertía acerca del peligro inscrito en el pasaje del enemigo político al enemigo absoluto y su consecuencia inmediata, la despolitización y por ende, la destrucción absoluta; mientras que el segundo da cuenta de la locura auto-inmune, que se desata en el momento en que se busca el aniquilamiento del otro: al eliminar al enemigo, se generaría una violencia inaudita, un retorno de la agresividad sobre la comunidad en sí misma. Lo anterior se desprende de observar en los acontecimientos políticos contemporáneos, la aparición de múltiples puntos de fractura: el auge de discursos nacionalistas, xenofóbicos, del aumento en los feminicidios, la crisis de migrantes, las muertes producidas por el narcotráfico y el crimen organizado, la trata de personas, entre otros; expresiones de una violencia generalizada, en la cual parece imperar una relación de identidad entre el enemigo y su aniquilación.

Tomando en cuenta lo anterior, la cuestión que articula este artículo es cómo pensar lo político cuando las sociedades contemporáneas están atravesadas por una locura auto-inmune, con el objetivo último de eliminar definitivamente al enemigo. En esta línea, el concepto de necropolítica propuesto por Mbembe (2011) brinda una aproximación sugerente sobre la cual pensar estos fenómenos, ya que para el autor, la política contemporánea hace del asesinato del enemigo su objetivo primero y absoluto, con el pretexto de la guerra, de la resistencia o de la lucha contra el terror (Mbembe, 2011, p. 20). Así, con base en estos aportes, interesa discutir alrededor de la interrogante de si estamos frente a un fenómeno político novedoso, o si estas políticas de la muerte son un efecto recrudecido de la conjunción democracia liberal-procedimental y capitalismo.

Con este objetivo, el artículo se divide en dos secciones. En la primera, se expone el concepto de lo político, distinguiéndolo de la política administrativa, como forma de lazo social bajo la cual se constituye, instituye o funda la comunidad, desde una lectura que incorpora aportes de la teoría política y el psicoanálisis (Freud, 1992a, 1992b, 1992c; Lacan, 1961-1962, 1999, 2009; Schmitt, 1966, 2009a, 2009b). Luego, con base en lo anterior, en la segunda sección se discute si la propuesta de Mbembe puede ser leída en términos de una mutación en lo político y, por tanto, supone una transformación de las coordenadas simbólicas que 
permiten el surgimiento de la comunidad, o si es un efecto de una configuración previa que ha adquirido rasgos extremos. En otras palabras, se trata de analizar si hay una línea de continuidad entre la forma en cómo se entiende el enemigo político, el enemigo absoluto y el enemigo en la necropolítica, o si serían fenómenos políticos y psíquicos diferenciados.

\section{LO POLÍTICO COMO ESCENARIO ANTAGÓNICO}

Si bien la aparición de la división entre los conceptos de lo político y la política es relativamente reciente, el concepto de la política no ha estado exento de transformaciones en su significado, desde sus primeras teorizaciones en la Grecia antigua hasta la contemporaneidad. En ese sentido, es un concepto que ha acumulado un caudal de experiencias que se han sedimentado a lo largo de distintas épocas: es un concepto de registro de experiencias [Erfahrungsregistraturbegriff], que a su vez puede generarlas - concepto generador de experiencias [Erfahrungsstiftungsbegriff] (Koselleck, 2012, p. 36) -; e inclusive, puede llegar a ser un concepto que se alimenta de contenidos utópicos, puede ser un concepto de expectativas [Erwartungsbegriff] (Koselleck, 2012, p. 37).

Esta apertura radical, que se desprende de las propiedades del lenguaje y que afecta a las palabras en general, nos muestra que los desplazamientos de sentido no suponen una ruptura radical con el pasado, sino más bien la coexistencia de múltiples niveles de sentido: supone una coetaneidad en el tiempo. Es por esta razón que interesa señalar dos puntos de inflexión en el significado del concepto de la política, ya que se considera que éstos han configurado nuestra concepción contemporánea de la misma: el realizado por Maquiavelo, que rompe con la tradición de asociar a la política a otras esferas de pensamiento; y la introducción de la distinción entre lo político y la política dentro del pensamiento continental del siglo XX. Expondré el primer desplazamiento de forma breve, ya que el interés estará depositado en el segundo, para efectos del tema que nos interesa.

Maquiavelo instala la noción según la cual la política es una esfera autónoma, en contraste con las tradiciones griega, romana y cristiana, las cuales, respectivamente, habían asociado la política con la ética, con lo jurídico y con la teología ${ }^{1}$. No obstante, la autonomía no se plantea en sentido absoluto, sino en sentido relativo, a partir de los siguientes criterios: 1) la política es diferente; 2) la política tiene sus propias leyes, con lo cual es independiente de otros aspectos de la vida; 3) es autosuficiente y autárquica, puede ser explicada desde sí misma; y 4) la política adquiere carácter de causa primera, ya

1 Se puede entender este desplazamiento como un indicio del pasaje a la Modernidad, como una expresión temprana de la disolución de los indicadores tradicionales de certeza (Lefort, 1990, p. 188). 
que no sólo se genera a sí misma, sino que genera todo lo demás (Sartori, 1973, pp. 1011). Empero, es importante destacar que ninguno de los sentidos atribuidos previamente desaparece, lo que se modifica es el estatuto que adquiere la política frente a estos.

De esta manera, con Maquiavelo la política se separa de los discursos de la ética, de lo jurídico y de lo teológico: ya no actúan como sus supuestos indisolubles, sino que actúan como medios para un fin. La ética, la religión y el aparato jurídico se convierten así en instrumentos para la política. La política posee sus propias leyes, mismas que un buen "príncipe" debe saber aplicar (Sartori, 1973, p. 11). Por consiguiente, esta doctrina del príncipe, o la posterior teoría jurídica del soberano, marcó la discontinuidad entre el poder del príncipe y cualquier otra forma de poder (Foucault, 1978, pp. 194-195), a la vez que separó al Estado de la naturaleza y de la divinidad:

El Estado se gobierna según las leyes racionales que le son propias, que no se deducen de las solas leyes naturales o divinas, ni de los solos preceptos de sabiduría y de prudencia; el Estado, como la naturaleza, tiene su propia racionalidad, aunque sea de un tipo diferente. Al contrario, el arte de gobernar, en vez de ir a buscar sus fundamentos en reglas trascendentes, en un modelo cosmológico o en un ideal filosófico y moral, deberá encontrar los principios de su racionalidad en aquello que constituye la realidad específica del Estado (Foucault, 1978, p. 204).

En consecuencia, esta forma de comprender a la política, que daría emergencia a las teorías de razón de Estado, tenía como objetivo responder a la pregunta de cómo gobernarse, cómo ser gobernado, cómo gobernar a los demás, por quién se debe aceptar ser gobernado y qué hacer para ser el mejor gobernante (Foucault, 1978, p. 188). Este proceso se aceleró e intensificó con la teoría hobbesiana del soberano. Hobbes, influenciado por esta nueva forma de pensar al mundo, concluye que las leyes de la política podían ser creadas por el Leviatán, y que no eran producto de una externalidad como lo pensaba Maquiavelo. El Leviatán no gobernaba de acuerdo con las leyes de la política, sino que éste tenía la potestad de crear esas leyes. El mundo aparece como infinitamente manipulable, siendo el Leviatán el manipulador absoluto (Sartori, 1973, p. 12).

Este tipo de racionalidad del poder del Estado es definida por Foucault (1990, p. 121) como una racionalidad reflexiva y perfectamente consciente de su singularidad. La doctrina de razón de Estado intentaba definir de qué manera los principios y métodos del gobierno eran distintos de los aplicados en la esfera divina, en la esfera familiar o en la esfera de un superior frente a su comunidad. Es una realidad específica y discontinua que no podía asimilarse o fundirse con algo semejante a una estructura imperial que representara, de alguna manera, una teofanía de Dios 
en el mundo (Foucault, 2007, p. 20). Como veremos más adelante, esta forma de interpretar el poder soberano está presente en el decisionismo schmittiano (Schmitt, 2009a, p. 69), y permea la forma en cómo los Estados contemporáneos deciden quién debe vivir y quién debe morir (Mbembe, 2011, p. 20).

El segundo desplazamiento, que brinda las bases para dar la discusión materia de este estudio, es la distinción entre lo político y la política; que aparece por primera vez en el pensamiento alemán en 1927 con la obra El concepto de lo político $^{2}$ de Carl Schmitt; mientras que en el pensamiento francés emerge con el ensayo de Paul Ricoeur La paradoja política de 1957 (Marchart, 2009, p. 17). En este artículo, de estas dos posibles vías de interpretación de lo político, se dará énfasis a la versión schmittiana, dado que interesa observar cómo las dimensiones del poder, el conflicto y el antagonismo se presentan en la forma en cómo se conceptualiza al enemigo, antes que la visión que encarna Ricoeur, que piensa lo político como un espacio de comunalidad (Marchart, 2009, pp. 59-62).

Schmitt en su libro El concepto de lo político, da cuenta de lo que entiende por lo político. Su objetivo es delimitar con precisión algo estrictamente propio de esta distinción. Así lo especifica en su texto:

Si se aspira a obtener una determinación del concepto de lo político, la única vía consiste en proceder a constatar y a poner de manifiesto cuáles son las categorías específicamente políticas... Lo político tiene que hallarse en una serie de distinciones propias últimas a las cuales pueda reconducirse todo cuanto sea acción política en un sentido específico (Schmitt, 2009a, p. 56).

De este modo, a Schmitt lo que le interesa es proponer un análisis del campo de relaciones de lo político, específicamente en lo concerniente a sus relaciones de intensidad ${ }^{3}$. Propone como criterio específico de lo político la relación entre amigo-enemigo:

La oposición o el antagonismo constituye la más intensa y extrema de todas las oposiciones, y cualquier antagonismo concreto se aproximará

\footnotetext{
2 Si bien hay tres versiones reconocidas del texto de Schmitt (1927, 1932 y 1933), en este artículo se utiliza la versión de 1932.

3 Derrida (1998, pp. 153-155) encuentra que este criterio de intensidad es problemático, porque diluye las fronteras entre lo político y la guerra, asignando un telos a lo político. Tal como lo plantea Arditi (2012, p. 12): "Para Jacques Derrida el uso de la intensidad es problemático pues tiende a disolver las fronteras entre guerra y política que el propio Schmitt se esmera en resguardar. Esto se debe a que si bien Schmitt usa la intensidad como calificativo de su criterio amigo-enemigo para distinguir con más claridad las oposiciones políticas de las no políticas, no se da cuenta de que al hacerlo está asignando un telos a lo político. Con la intensidad, dice Derrida, la guerra termina siendo la esencia y el destino de lo político y no simplemente su presupuesto o caso excepcional".
} 
tanto más a lo político cuanto mayor sea su cercanía al punto extremo, esto es, a la distinción entre amigo y enemigo (Schmitt, 2009a, p. 59).

De esta distinción, el autor alemán se concentrará en definir al enemigo político:

El enemigo político no necesita ser moralmente malo, ni estéticamente feo; no hace falta que se erija en competidor económico, e incluso puede tener sus ventajas hacer negocios con él. Simplemente es el otro, el extraño, y para determinar su esencia basta con que sea existencialmente distinto y extraño en un sentido particularmente intensivo. En último extremo pueden producirse conflictos con él que no puedan resolverse ni desde alguna normativa general previa ni en virtud del juicio o sentencia de un tercero "no afectado" o "imparcial" (Schmitt, 2009a, p. 57).

Ahora, a esta primera precisión, que es un criterio descriptivo, se le agrega un principio existencial. Como él mismo lo plantea, el enemigo no es cualquier competidor o adversario, sino aquel conjunto de seres humanos que eventualmente, con una posibilidad real, se opone combativamente a otro conjunto análogo:

Los conceptos de amigo, enemigo y lucha adquieren su sentido real por el hecho de que están y se mantienen en conexión con la posibilidad real de matar físicamente. La guerra procede de la enemistad, ya que ésta es una negación óntica de un ser distinto. La guerra no es sino la realización extrema de la enemistad (Schmitt, 2009a, p. 63).

En otro lugar define a esta posibilidad extrema como la forma en la que el ser humano adquiere su tensión política:

Pues sólo en la lucha real se hace patente la consecuencia extrema de la agrupación política entre amigos y enemigos. Es por referencia a esta posibilidad extrema como la vida del hombre adquiere su tensión específicamente política (Schmitt, 2009a, p. 65).

A estos dos criterios se le anteponen varias distinciones. La primera es que el enemigo debe ser público, antes que un enemigo privado o familiar, hostis en lugar de inimicus $^{4}$ (Schmitt, 2009a, p. 59). De acuerdo con Arditi (2012, p. 13), esta preferencia por el vocablo hostis no es accidental, ya que para el autor las oposiciones políticas se fundan en la hostilidad mutua de dos bandos enfrentados; condición que a su vez, no implica necesariamente desembocar en una guerra. La consecuencia inmediata de que este enemigo se constituya en el ámbito público, es que solamente el Estado en tanto unidad política puede definir cuál o cuáles

$4 \quad$ Inimicus significa enemigo, pero para los romanos aplicaba solamente a las enemistades personales y privadas, mientras que hostis designaba al ejército o pueblo enemigo. 
son los enemigos a través de la decisión (Schmitt, 2009a, p. 73). Por consiguiente, se excluye de esta caracterización la presencia de enemigos privados o, inclusive, de enemigos dentro del mismo Estado (Schmitt, 2009a, pp. 58-59). En este punto conviene recordar que Schmitt desarrolla esta teoría en el marco del derecho internacional, sin embargo, de esto no se deriva una imposibilidad de trasladar el criterio mínimo de lo político a disputas dentro de un mismo Estado, o como veremos más adelante, extender el criterio a las comunidades políticas en general. Lo anterior se puede sustentar con el siguiente extracto:

Todo antagonismo u oposición religiosa, moral, económica, étnica o de cualquier clase se transforma en oposición política en cuanto gana la fuerza suficiente como para agrupar de un modo efectivo a los hombres en amigos y enemigos. Lo político no estriba en la lucha misma; ésta posee a su vez sus propias leyes técnicas, psicológicas y militares. Lo político está, como decíamos, en una conducta determinada por esta posibilidad real, en la clara comprensión de la propia situación y de su manera de estar determinada por ello, así como en el cometido de distinguir correctamente entre amigos y enemigos (Schmitt, 2009a, p. 67).

De este modo, queda claro que lo político extrae su fuerza de distinciones y compromisos no políticos, por lo cual es parasitario en un sentido no peyorativo. Lo político como tal no tendría un espacio o contenido propio, sino que surge o se monta sobre fenómenos extrapolíticos, depende de objetos externos a sí mismo para existir: "Opera en el espacio de los otros" (Arditi, 2012, p. 29).

A partir de lo anterior, se extraen las siguientes consecuencias. En primer lugar, esta propuesta de construcción de dicotomías entre amigos y enemigos lleva implícita una lectura acerca de lo que significa el sujeto para Schmitt, y a su vez, de cómo se construye el lazo social dentro de la comunidad política. Schmitt plantea aquí una visión heredera de los planteamientos de Maquiavelo y Hobbes, ya que supone que el poder soberano es en última instancia aquel que puede decidir quién es el enemigo y, por ende, a quién se le puede dar muerte y a quién no. En segundo lugar, Schmitt procura evitar cualquier referencia a un enemigo naturalizado o histórico, es decir, deja abierta la posibilidad de que esta distinción sea flexible y responda a formas particulares de constitución de lo político en los sujetos, que para constituirse como tales, necesitan de un enemigo que les pueda dar referente: no hay uno sin otro: "El límite entre lo propio y lo extraño es variable y funciona como una membrana que aísla y, a la vez, mantiene en contacto" (Serrano Gómez, 1998, p. 45). Finalmente, Schmitt deja en claro que el establecimiento de cualquier comunidad política se da cuando se identifica al enemigo. 
La identificación y, subsecuentemente, la exclusión del enemigo (como el otro y el extraño), establece el pasaje entre la comunidad y la comunidad política, el otro del otro: el otro del otro, es el sí mismo (Ojakangas, 2003, p. 412).

La segunda distinción aparece en el Corolario II Sobre la relación entre los conceptos de guerra y enemigo (1938), y se desprende del análisis que Schmitt realiza de las diferentes formas de nombrar el enemigo. Así, encuentra que en alemán es oscura la etimología de la palabra para enemigo (Feind), pero al menos hay acuerdo en que el sentido lingüístico designa aquél contra el cual se inicia una Fehde (disputa, querella, contienda) (Schmitt, 2009b, p. 133). Por otro lado, advierte que en inglés el término enemy ha hecho caer en desuso la palabra germánica foe, que designaba al adversario mortal, y más tarde al enemigo en general (Schmitt, 2009b, p. 134). Sin embargo, veinticinco años después, encuentra que ha habido un resurgimiento del uso de la palabra foe en contraposición a enemy, desplazamiento conceptual que interpreta como resultado del aumento en los medios de aniquilación, y cómo esto ha desdibujado la distinción entre guerra y paz (Schmitt, 2009c, p. 48). Lo anterior es leído por Arditi (2012, p. 15) como un indicador de que para Schmitt existe una distinción entre el enemigo político y el enemigo mortal, el cual no sería un enemigo político en estricto; no obstante, tal como se presentará más adelante, existen ambigüedades relativas al criterio existencial que podrían poner en duda esa interpretación.

En cualquier caso, ya sea que decantemos o no por la apreciación de Arditi, parece que el autor encuentra obstáculos para establecer una clara distinción conceptual, que se derivan de lo que él observa, una imposibilidad para distinguir entre guerra y paz, propia del orden político y jurídico de la época:

Ya se decida, pues, que hay guerra porque no hay paz, o que hay paz porque no hay guerra, en uno y otro caso habría que empezar por preguntar si realmente existe algún tercero, alguna posibilidad intermedia, o si no hay nihil medium. Sería desde luego algo anómalo, pero es que justamente existen situaciones anómalas. Y en la actualidad se da una de esas situaciones intermedias entre guerra y paz, en la que ambas cosas están mezcladas. Tres son las causas: en primer lugar, los dictados de paz de París; en segundo lugar el sistema de prevención de la guerra organizado durante la postguerra con el pacto de Kellogg y la Sociedad de las Naciones; y en tercer lugar la expansión de la idea de la guerra a actividades de hostilidad también extramilitares (económicas, propagandísticas, etc.). Pues los mencionados dictados de paz pretendían convertir la paz en una "prosecución de la guerra con otros medios". Llevaron tan lejos el concepto de enemigo que acabaron no sólo con la distinción entre combatiente y no combatiente, sino incluso con la de guerra y paz. Pero 
al mismo tiempo intentaron legalizar por medio de pactos este estado intermedio, tan indeterminado y deliberadamente mantenido en suspenso, y hacer como si jurídicamente fuese el status quo de la paz normal y definitivo (Schmitt, 2009b, pp. 135-136).

Esta ambigüedad conceptual será objeto de tratamiento en Teoría del partisano, no sin dificultades. En este texto, establece una tercera y última distinción entre enemigo convencional, real y absoluto (Schmitt, 1966, pp. 20, 72-74, 77, 8283, 124). Empero, antes de exponerla, es necesario retomar el hilo acerca de la condición necesaria de la enemistad que se abrió con El concepto de lo político.

En ese libro, el autor deja claro que el conflicto es un fenómeno insuperable del mundo, ligado a la formación y defensa de las identidades particulares ${ }^{5}$. Por consiguiente, cualquier intento de superar este conflicto inherente a la condición humana conduce a una intensificación de la lucha, ya que si se aspira a eliminar el conflicto se crea una frontera antagónica que solo puede ser resuelta a través de una "guerra al conflicto":

Nada puede sustraerse a esta consecuencia de lo político. Y si la oposición pacifista contra la guerra llegase a ser tan fuerte que pudiese arrastrar a los pacifistas a una guerra contra los no pacifistas, a una "guerra contra la guerra", con ello quedaría demostrada la fuerza política de aquella oposición, porque habría demostrado tener suficiente fuerza como para agrupar a los hombres en amigos y enemigos. Si la voluntad de evitar la guerra se vuelve tan intensa que no retrocede ya ante la misma guerra, es que se ha convertido en un motivo político, esto es, que ha acabado firmando la guerra e incluso el sentido de la guerra, aunque sólo sea como eventualidad extrema (Schmitt, 2009a, p. 66).

Schmitt discute, por tanto, contra las teorías políticas que procuran una reducción del conflicto. Encuentra que una teoría que procure una reconciliación universal está siendo generada por una "Razón" delirante, que deja de lado que la condición indispensable para reconciliar el orden social y el conflicto es aceptar que el conflicto es inherente a la constitución de comunidades políticas: "Schmitt mantiene que la relación amigo - enemigo es un "hecho existencial básico"; lo cual implica sostener que la política y la forma de conflicto ligada a ella son determinaciones insuperables de la condición humana" (Serrano Gómez, 1998, p. 43). Por consiguiente, Schmitt plantea que la existencia de ciertos órdenes sociales particulares en cada época es el resultado contingente

$5 \quad$ Es en este punto donde se empieza a observar el paralelismo entre algunos preceptos de la obra de Schmitt con las propuestas de Freud acerca de la constitución de la comunidad humana. Se profundizará más adelante. 
de un conflicto permanente. En tanto no hay esencia del "ser humano", tampoco se puede plantear un orden universal necesario al que deban adecuarse todas las sociedades, ni se puede proponer la existencia de valores o normas universales, sino que estas responden a un contexto particular y a las decisiones que en cada contexto han tomado los individuos:

(...) si, en consecuencia, desapareciese hasta la eventualidad de la distinción entre amigo y enemigo, en tal caso lo que habría sería una acepción del mundo, una cultura, una civilización, una economía, una moral, un derecho, un arte, un ocio, etc., químicamente libres de política, pero no habría ya ni política ni Estado (Schmitt, 2009a, p. 83).

Un conflicto de este tipo adoptaría la forma de la guerra última de la humanidad, caracterizada por tener una intensidad e inhumanidad insólitas, ya que van más allá de lo político y degradan al enemigo a través del uso de categorías morales o de otros tipos, con lo cual se convierte en el horror humano que no sólo hay que rechazar sino que hay que aniquilar definitivamente (Schmitt, 2009a, p. 66).

Schmitt (2009a, p. 84) introduce acá dos formas bajo las que se puede negar la calidad de ser humano al enemigo, que sería declararlo hors-la-loi ${ }^{6}$ y hors l'humanité $^{7}$, con lo cual se justificaría llevar así una guerra hasta la más extrema inhumanidad. En contraposición a esto, el autor aboga a favor del sostenimiento del enemigo político, que no es considerado como un obstáculo en la realización de valores absolutos o como una amenaza de la humanidad, sino que tiene derecho a declarar la guerra y a firmar un tratado de paz (Serrano Gómez, 1998, p. 67).

Ahora bien, en Teoría del partisano estas preocupaciones llevan a la distinción previamente mencionada, la cual intenta responder a las transformaciones que estaban aconteciendo en el orden político y jurídico de la época; en específico, la aparición de categorías bélicas y tipos de enemistad que desbordaron lo que era el derecho clásico de guerra - jus publicum Europaeum - , en el cual la enemistad estaba acotada a territorios en específico y establecía inequívocamente la diferencia entre guerra y paz, combatientes y no combatientes, de enemigo y criminal (Schmitt, 1966, p. 18).

En ese sentido, a partir del estudio de la figura del partisano, problema que emerge a partir de la guerrilla que hizo el pueblo español contra el ejército napoleónico durante el periodo de 1808 a 1813 (Schmitt, 1966, p. 11), Schmitt denuncia lo que considera la aparición de otro tipo de enemistad, una enemistad "verdadera" que desborda la acotación y domesticación de la guerra convencional, y

$6 \quad$ Fuera de la ley. Traducción libre.

7 Fuera de la humanidad. Traducción libre. 
que en sus palabras "[...] se enreda en un círculo de terror y contraterror hasta la aniquilación total" (Schmitt, 1966, p. 20). Si bien no interesa profundizar en esta distinción, lo relevante para nuestra discusión es que Schmitt reconoce que las reglas del juego de una guerra acotada se habían transformado, mostrándose ineficientes frente a la aparición de tropas irregulares que cancelaban las categorías de combatiente y no combatiente (Schmitt, 2009b, p. 138), ejército regular e irregular, legal o ilegal (Schmitt, 1966, pp. 24-27; 50-51); eliminando la posibilidad de pensar en un enemigo convencional al cual se combate bajo reglas preestablecidas y se le respeta su humanidad (Schmitt, 1966, pp. 47, 97-98, 122).

Sin embargo, la indeterminación del concepto del enemigo no se detiene con el fenómeno del partisano, ya que Schmitt considera otros dos tipos de guerra que fueron dejados al margen por el derecho público europeo: la guerra civil y la guerra colonial (Schmitt, 1966, p. 20). Esta puntualización es de suma importancia, ya que parece ser que Schmitt reconoce que la idea de una enemistad acotada era solo posible en el marco del derecho jurídico europeo y sus líneas de amistad internacionales, que establecía un status quo bajo el cual se distinguían territorios donde la guerra era permitida y otros en los cuales estaba prohibida (Schmitt, 2005, pp. 221-274); de lo que se deriva que la desestabilización del concepto del enemigo y la perplejidad que introdujo fue sintomática solo para el mundo europeo, no para sus colonias ${ }^{8}$. Esta discusión será retomada más adelante cuando se analice la propuesta de Mbembe sobre necropolítica.

Esta vacilación conceptual señala una tensión entre la experiencia y el concepto, una dificultad para aprehender una serie de fenómenos que habían sido excluidos de la racionalidad jurídica europea y que, por ende, parecían escapar a lo que podría ser pensable como una forma de conflicto bélico. Inclusive, el impacto fue mayor en tanto esta exclusión no significó en ningún momento su desaparición; al contrario, este tipo de guerra se desarrolló y adquirió prevalencia en el siglo XX. Su consecuencia inmediata fue poner en tela de juicio la interpretación hegemónica europea acerca de la guerra y la paz, del amigo y del enemigo, precipitando un desplazamiento semántico que desestabilizó las formas previas de comprensión del conflicto político; y por lo tanto, de la noción de comunidad.

Schmitt quiso resolver este impasse apelando a la diferencia que puede existir entre un enemigo absoluto y un enemigo real y/o convencional. Para el primero, la guerra no tiene límites, es una guerra total (Schmitt, 1966, pp. 44-45, 72-74; 123-124). Es una guerra que identifica al enemigo como criminal y con ello legitima su aniquilación. Al contrario que el enemigo real, que no declara a su enemigo político como enemigo último de la humanidad (Schmitt, 1966, p. 127), el enemigo absoluto arriesga no solo su vida, sino que puede declarar y ser de-

8 Si se quiere profundizar en este análisis, consultar el texto El nomos de la tierra (2005). 
clarado - por eso el círculo del terror aniquilatorio - como alguien fuera de la ley, el derecho y el honor. En este juego de espejos entre los unos y los otros, los unos califican de trampa ideológica las nociones que tienen los otros de ley, derecho y honor: "El ejecuta la pena capital contra un criminal, y corre por su parte el riesgo de que lo traten como criminal o antisocial" (Schmitt, 1966, p. 45).

Para Schmitt, la encarnación por antonomasia de esta forma de enemistad se da en la figura del combatiente revolucionario, la cual encuentra plenamente desarrollada por Lenin (Schmitt, 1966, pp. 73-74, 127). Para el jurista alemán, fue Lenin quien verdaderamente comprendió los alcances de la enemistad absoluta, que la violencia y la guerra sangrienta eran inevitables en aras de alcanzar sus objetivos políticos (Schmitt, 1966, p. 70). El sentido de la confrontación le otorga su condición de lo justo, justifica y legitima la confrontación total:

La guerra de enemistad absoluta no conoce ningún acotamiento. La realización consecuente de una enemistad absoluta le da su sentido y su justicia. Hay solo una cuestión: existe un enemigo absoluto y, ¿quién es in concreto? Lenin no dudaba ni un momento en la contestación. Era superior a todos los demás socialistas y marxistas precisamente porque tomaba en serio la enemistad absoluta. Su enemigo absoluto era el enemigo de clase, el burgués, el capitalista occidental con su orden de sociedad en todos los países donde esté en vigor (Schmitt, 1966, p. 74) .

En términos formales, más allá del sesgo ideológico del autor, parece que Schmitt se encuentra en este punto con algo que le perturba, que es la idea de una transformación total del orden de sociedad. Esta posibilidad generaría un antagonismo más allá de la política, en el cual la violencia se desplegaría sin límites y no habría ningún acotamiento. Por esta razón es que el autor excluye a este tipo de enemistad de la consideración acerca de lo político, ya que en ese punto no habría más que la imposición violenta de una única forma de entender el orden. Más allá de los señalamientos realizados por Leo Strauss (2008) en su Comentario sobre El concepto de lo político de Carl Schmitt, de que Schmitt tendría un juicio moral no asumido acerca de la bondad del orden; o como plantea Arditi (2012, pp. 15-16, 33) de que habría un supuesto normativo implícito operando en esta apuesta por el orden y en la exclusión del enemigo absoluto; lo que nos interesar marcar es la dificultad que tiene Schmitt para comprender estas variaciones en torno a la enemistad: ¿cómo establecer un límite a la confrontación cuando esta parece desbordarse en todo momento? ¿Cómo abordar el desafío que implica desarrollar una teoría formal de lo político cuando la experiencia excede la conceptualización? Tal como discute Derrida (1998, pp. 133-136), el

$9 \quad$ El segundo énfasis ha sido marcado por la autora. 
proyecto schmittiano proyecta una tensión, entre el reconocimiento del estatuto polémico de los conceptos políticos y la pretensión de una teoría conceptual pura y rigurosa de lo político.

En ese sentido, la pretensión schmittiana de purgar lo político de aquello que lo contaminaría (Arditi, 2012, pp. 26-27), de distinguir entre diversos tipos de enemigo, choca con la realidad que la desborda. En palabras de Derrida (1998, p. 134), de aquí se puede extraer una conclusión práctica, la cual es que la política como tal es una praxis, y se escapa constantemente de la adecuación a un concepto:

El concepto de lo político corresponde sin duda, como concepto, a lo que el discurso ideal puede querer enunciar como más riguroso acerca de la idealidad de lo político. Pero ninguna política ha sido adecuada jamás a su concepto. Ningún acontecimiento político puede ser correctamente descrito o definido con la ayuda de estos conceptos. Y esta inadecuación no es accidental, desde el momento en que la política es esencialmente una prâxis, cosa que implica siempre el propio Schmitt cuando recurre de forma tan insistente el concepto de posibilidad o de eventualidad reales y presentes en sus análisis de las estructuras formales de lo político (Derrida, 1998, p. 134).

Esta imposibilidad no solo está ilustrada por este objeto inencontrable, sino que además habita otros puntos críticos del razonamiento schmittiano, por ejemplo, la distinción entre stásis y pólemos (Derrida, 1998, p. 133); la ambigüedad entre el Estado o la comunidad como unidad política decisiva (Arditi, 2012, p. 35); y el límite o frontera entre los diferentes tipos de enemigo. Por el momento, interesa discutir este último.

Tal como se mencionó anteriormente, este criterio normativo que excluye al enemigo absoluto de lo que puede ser considerado político pone en cuestión el criterio existencial. En otras palabras, si el agrupamiento entre amigos y enemigos supone la posibilidad real de matar físicamente (Schmitt, 2009a, p. 63); ¿dónde estaría el límite mencionado entre un enemy o un foe? ¿Es un límite cuantitativo o cualitativo? ¿Bajo qué condiciones se considera que la enemistad real ha hecho su pasaje a la enemistad absoluta?

La propia obra schmittiana nos brinda dos pistas para transitar sobre esta ambigüedad y escapar de esta tentación del purismo conceptual, retomando la preocupación del autor acerca de aquello que estaría más allá de la política. La primera, es una idea que aparece repetidamente en El concepto de lo político, acerca de la humanidad del enemigo. Para Schmitt, el punto de quiebre estaría marcado por la deshumanización del otro, por la imposibilidad de pensar-lo como un ser humano 
con el cual se pueden establecer vínculos, negociar e inclusive comerciar (Schmitt, 2009a, p. 59). En tanto Schmitt encuentra como criterio de lo político una relación que es a su vez constitutiva y polémica; constitutiva porque permite definir los límites de la comunidad, el adentro y el afuera, los amigos y los enemigos de forma pública; polémica en tanto esta definición se encuentra en-construcción, no son definiciones absolutas o eternas; la imposibilidad de identificar al otro como semejante en la diferencia, tiene por consecuencia la pérdida de la dimensión productiva del conflicto, misma que permite la construcción de movimientos sociales, partidos o Estados (Arditi, 2012, p. 18). Como veremos más adelante, lo que nos alerta la previsión normativa es que Schmitt intuye que habría un punto de no retorno sobre el cual ya no es posible la comunidad política de amigos, un antagonismo mortífero que ya no sería "productivo". Sin embargo, el autor avanza hasta ahí. No indica cómo se sobrepasa ese límite, dónde estaría justo el punto en el cual el enemigo pasa de ser un exterior constitutivo (Staten, 1984, pp. 15-19), a aquel que destruye las propias condiciones de posibilidad de la comunidad política.

Una segunda pista remite a un criterio tecnológico. Schmitt (1966, p. 128) observó con preocupación el aumento de la capacidad aniquilatoria de las armas, a las cuales denominó "supraconvencionales". Inclusive, llegó a plantear que este tipo de arma supone un tipo distinto de ser humano, que no sería capaz de regular esta espiral mortífera. Si bien no interesa discutir a profundidad el vínculo íntimo que ha tenido la guerra y la tecnología a lo largo de la historia, se puede extraer de esta apreciación el hecho de que un ser humano capaz de generar grandes pérdidas humanas con menor esfuerzo, puede fácilmente deshumanizar al enemigo. Así, dos condiciones, la deshumanización y la masificación de los medios de destrucción, nos brindan el punto clave de la preocupación schmittiana:

Nuevas especies de enemistad absoluta tienen que surgir en un mundo en donde los contrincantes se empujan unos a otros hacia el abismo de la desvalorización total antes de aniquilarse físicamente. La enemistad se hará tan horrorosa que ni siquiera se podrá hablar de enemigo y enemistad. Ambos se proscribirán y condenarán en debida forma antes de empezar con la obra de destrucción. La destrucción se hará entonces completamente abstracta y absoluta. Ya no se dirige contra un enemigo, sino que servirá a la imposición, llamada objetiva, de valores supremos, y éstos, como es sabido, no tienen precio. Sólo la negación de la enemistad verdadera abre el camino para la obra destructora de la enemistad absoluta (Schmitt, 1966, p. 129).

Por tanto, Schmitt está planteando una teoría de la violencia controlada dentro de los marcos del Estado (Villegas Contreras, 2003, p. 63). Si se acepta como condición o 
supuesto que el enemigo es simplemente otro, que toma decisiones de carácter normativo distinto, con otros marcos de explicación y no es una criatura malvada que viola valores universales, se puede llegar a un compromiso (no un entendimiento) que permita reglamentar el conflicto (Serrano Gómez, 1998, p. 49). De esta manera, Schmitt concibe al orden como necesario y el conflicto como lo contingente, que puede reducirse al mínimo a través de una solución de compromiso (Serrano Gómez, 1998, p. 55).

Ahora, más allá de que se le pueda criticar a Schmitt una idealización del jus publicum europeum $^{10}$, y un sospechoso olvido y/o selección de acontecimientos bélicos a lo interno del territorio europeo en los cuales hubo aniquilación, que hubieran supuesto una invalidación de su planteamiento; conviene destacar el llamado a comprender al conflicto como la condición de posibilidad de la comunidad política - más allá de sus inconsistencias con respecto a si es el Estado el soberano por excelencia o el pueblo -, y que esto supone la identificación del otro. A esto habría que añadir una crítica, la cual es consecuencia de la ya mencionada pretensión de pureza conceptual, brillantemente abordada por Derrida (1998, pp. 133-136): a Schmitt se le olvida que las relaciones de amistad y enemistad producen afectos, como si la larga tradición iniciada por Aristóteles que vincula la amistad y sus afectos con la comunidad política no hubiera sido relevante o no existiera. Es claro que intentar dar una respuesta a esta ausencia solamente nos llevaría por los caminos de la especulación, pero esto no quiere decir que no se pueda trabajar sobre esta; ya que este vacío teórico-conceptual tiene por consecuencia que no exista en Schmitt una aproximación mínima acerca de cómo el otro puede perder su humanidad, cómo se pasa de un enemigo al cual puedo amar en privado (Derrida, 1998, p. 107), de un enemigo que "es nuestra propia pregunta como persona", (Schmitt, 1966, p. 118) al deseo de su desaparición física e histórica.

Así, en aras de abordar este nudo problemático, propongo una lectura alternativa a la propuesta de Schmitt, desde una mirada que incluya lo político como una forma de constitución del lazo social en dos momentos, en donde el primer momento de éste sería la constitución de un nosotros y un ellos, en el cual se establecen los límites de la comunidad; y el segundo momento sería resultado el de una decisión discrecional en el cual se identifica a ese ellos como enemigo. Esta línea interpretativa brinda una apertura, no solamente para pensar la conformación de las comunidades políticas, que era el interés confeso de Schmitt, sino también para pensar en cómo se construye ese lazo social entre los sujetos que conviven en un mismo espacio y tiempo.

10 "Porque la humanidad europea había conseguido algo único con aquellos acotamientos de la guerra: el prescindir de la criminalización del adversario de guerra, es decir, una relativización de la enemistad, la negación de la enemistad absoluta. Es algo muy raro, humanamente inverosímil, que los hombres consientan en prescindir de una discriminación y difamación de sus enemigos" (Schmitt, 1966, p. 124). 


\section{LO POLÍTICO COMO FORMA DE LAZO SOCIAL}

Las teorías psicoanalíticas freudiana y lacaniana, con su énfasis en los procesos afectivos del sujeto, permiten un acercamiento a la constitución de comunidades políticas que va más allá de plantearlas como la simple agrupación racional entre sujetos que comparten cierto contenido normativo, ya que dentro de éstas hay expresión de afectos o pasiones que afectan la forma en cómo se establecen las agrupaciones y cómo se manifiestan en la esfera pública.

Freud abordó la pregunta acerca de cómo se desarrolla y se expresa esta dependencia estructural entre el sujeto y el otro a partir del concepto de identificación. Para Freud, es a través de la identificación ${ }^{11}$ con otro que se crea la más temprana exteriorización de una ligazón afectiva con otra persona (Freud, 1992b, p. 99). No atañe en este punto dar los detalles de cómo se establece esta ligazón afectiva entre el niño y sus primeras figuras de amor, lo que interesa rescatar es que a través de la constitución del lazo social es como se establecen las relaciones dentro de una comunidad. En su ensayo titulado Psicología de las masas y análisis del yo (1921), Freud (1992b, p. 87) asume como premisa que los vínculos de amor son los que sostienen o generan el "alma" de las masas, ya que para exista una masa debe existir algún elemento que la cohesione. Para explicar esto, Freud (1992b, p. 91) toma por ejemplo lo que él considera son las dos masas artificiales por excelencia, la iglesia y el ejército. Si bien no es de interés profundizar en el análisis freudiano, sí es pertinente mostrar que para que exista una identificación de este tipo, debe existir una doble ligazón libidinosa: con el conductor (Cristo o el General en jefe) o una idea y con los otros sujetos de la masa ${ }^{12}$. Esto implicaría que, en clave schmittiana, las agrupaciones políticas no solamente compartirían el criterio existencial de la posibilidad de lucha y por ende de muerte, sino que compartirían afectos entre sí, hacia un supuesto líder o idea (Freud, 1992b, p. 95).

En este punto surge nuevamente la cuestión acerca de lo político como un concepto parasitario. La "masa" en términos freudianos no es un ente que dependa necesariamente de los designios de un líder o de un dios, sino que puede verse cohesionada por una idea, sea positiva o negativa:

11 Freud propone tres tipos de identificación: la identificación al padre, la identificación histérica y la identificación al líder. Si se quiere una mayor profundización, consultar la obra de Freud (1992b) Psicología de las masas y análisis del yo. Para los objetivos de este texto me concentraré en el tercero. 12 A primera vista, esto parecería contradecir el argumento schmittiano acerca de que lo político no tiene que ver con la moral, la estética o los afectos; sin embargo, esta posición no se sostiene frente a la expresión fáctica de los conflictos amigo - enemigo, ya que como se planteó anteriormente, lo político es un concepto parasitario, que adquiere su contenido de otras distinciones. Además, pretender generar una neutralidad afectiva cuando existe un conflicto de índole existencial (la posibilidad de lucha y por ende de muerte), parece ser una salida ingenua, en la cual se privilegiaría a la razón como principio rector de la acción, eliminando su contraparte afectiva o pasional. 
Una masa primaria de esta índole es una multitud de individuos que han puesto un objeto, uno y el mismo, en el lugar de su ideal del yo, a consecuencia de lo cual se han identificado entre sí en su yo (Freud, 1992b, pp. 109-110).

Ahora bien, hasta este punto Freud no hace más que describir cómo se genera la cohesión de un determinado grupo o comunidad, cómo se generan los amigos, pero todavía queda abierta la pregunta sobre la constitución de los enemigos. Esto tiene respuesta en la forma en cómo Freud elabora su teoría del dualismo pulsional.

En un escrito previo, en Más allá del principio del placer (1920) Freud (1992a) propone que dentro del ser humano estarían presentes dos grandes tendencias de la naturaleza: una pulsión de vida o agrupación (Eros) y una pulsión de muerte o destrucción. En otras palabras, no habría una condición moral que actúe como sustrato del comportamiento humano, sino que éste responde a un espectro en el cual las pulsiones se expresan, que puede ir desde el amor hasta la hostilidad o agresión. Con base en lo anterior, Freud se pregunta entonces cómo el ser humano se asocia con otras personas, qué ocasiona que se establezcan relaciones afectivas a pesar de que también existe esta hostilidad inherente o tendencia a mostrar agresividad. Su respuesta es que el sentimiento social descansa en la inversión de un sentimiento hostil hacia el otro a una ligazón de cuño positivo a través de la identificación (Freud, 1992b, p. 115). Esto posibilita que la hostilidad inherente sea desplazada del interior del grupo (nosotros) hacia otro grupo que actúa como receptáculo (ellos). En otras palabras, es a través de la identificación de uno con el otro que se puede garantizar la cohesión de la masa, y para que esto se sostenga, es necesario un grupo externo donde se deposite la hostilidad que no puede ser descargada en el interior del grupo.

En una obra posterior, en El malestar en la cultura (1930) Freud profundiza sobre estas ideas. En un análisis en algunos momentos similar al de Hobbes, Freud (1992c, p. 108) postula que esta cuota de agresividad inherente al ser humano tiene por consecuencia que se observe en el prójimo no sólo a un posible auxiliar o un posible objeto sexual, sino que existe una tentación de usarlo para satisfacer la agresión: homo homini lupus. Esta hostilidad primaria (Freud, 1992c, p. 109) es la que amenaza la disolución de la sociedad, frente a la cual la cultura ha creado mecanismos para intentar contener esta tendencia: se recurre a la identificación y a los vínculos amorosos de meta inhibida como métodos de contención. Sin embargo, el escape más común y sencillo a esta hostilidad se presenta en el menosprecio hacia los extraños: "Siempre es posible ligar en el amor a una multitud mayor de seres humanos, con tal que otros queden fuera para manifestarles agresión.” (Freud, 1992c, p. 111). 
Ahora bien, en el caso de Freud, es importante destacar que los vínculos identificatorios se producen sobre la base de una semejanza, de un reconocimiento de algo común entre unos y otros:

Si amo a otro, él debe merecerlo de alguna manera. Y lo merece si en aspectos importantes se me parece tanto que puedo amarme a mí mismo en él; lo merece si sus perfecciones son tanto mayores que las mías que puedo amarlo como al ideal de mi propia persona; tengo que amarlo si es el hijo de mi amigo, pues el dolor del amigo, si a aquel le ocurriese una desgracia, sería también mi dolor, forzosamente participaría de él. Pero si es un extraño para mí, y no puede atraerme por algún valor suyo o alguna significación que haya adquirido para mi vida afectiva, me será difícil amarlo. Y hasta cometería una injusticia haciéndolo, pues mi amor se aquilata en la predilección por los míos, a quienes infiero una injusticia si pongo al extraño en un pie de igualdad con ellos (Freud, 1992c, pp. 106-107).

Sin embargo, de esta conformación de un nosotros y un ellos como forma de constitución del lazo social, no se deriva necesariamente una relación antagónica, ya que si bien para Freud es en los ellos en quienes se deposita la agresividad, esto no implica una disposición existencial a la lucha. Por consiguiente, se puede plantear entonces la relación amigo - enemigo como una posible forma que adquiere el lazo social, como un segundo momento discrecional:

Por consiguiente, sería injusto reprochar a la cultura su propósito de excluir la lucha y la competencia del quehacer humano. Ellas son sin duda indispensables, pero la condición de oponente no coincide necesariamente con la de enemigo; sólo deviene tal cuando se la toma como pretexto y se hace abuso de ella. (Freud, 1992c, p. 109).

De esta breve exposición del pensamiento freudiano se pueden extraer dos ideas. La primera, es que la diferencia no es condición necesaria del antagonismo, y que su carácter productivo estaría dado desde la conformación de la distinción entre un nosotros y un ellos. La segunda, es que la agresividad, al ser un rasgo constitutivo del ser humano, no es eliminable, lo cual nos impone la tarea acerca de cómo convivir con ésta. En ese sentido, la dinámica pulsional descrita por Freud permite comprender el por qué el conflicto sería condición constitutiva de la comunidad, y por ende, de la comunidad política. Así, el pasaje entre la constitución de la diferencia entre nosotros y ellos estaría supeditado a una decisión discrecional, que transformaría el vínculo a otra forma de lazo social caracterizada por una tensión política. Sin embargo, esta decisión incorpora elementos de la psique que no necesariamente son accesibles a la consciencia, lo que agrega 
complejidad a la pregunta de cómo se establece el pasaje entre el enemigo real y el enemigo absoluto schmittiano. Sobre esto volveremos más adelante.

Por su parte, Lacan (1961-1962, p. 8) retomará esta relación de co-pertenencia entre el uno y el otro, entre nosotros y ellos, para replantear el concepto de identificación y trasladar su lectura hacia la forma en cómo el sujeto se posiciona con respecto al Otro ${ }^{13}$ y su búsqueda del sentido de la identidad. Para este autor, es en el redoblamiento del moi - même (mí mismo), como el sujeto se identifica como uno y como diferencia. Así, estudiará la identificación desde el segundo tipo propuesto por Freud (Einziger Zug), desde el cual Lacan diferenciará entre identificación imaginaria e identificación simbólica.

Para Lacan (2009a, p. 66) la identificación imaginaria se manifiesta por la imitación interna de las actitudes del otro, de la cual pretende lograr la justa apreciación de su objeto, a partir de la inauguración que brinda la imagen en el espejo:

(...) introduce la forma del otro en cuanto tal, es decir, como pura reciprocidad, puesto que el uno se reconoce más que en el otro y no descubre el atributo que es suyo sino en la equivalencia del tiempo propio de los dos (Lacan, 2009b. p. 202).

Por lo tanto, en lo imaginario el moi se identifica con el otro como su imagen, e identifica al otro especular con sí mismo como su imagen. El propio Lacan planteará que esta es la forma que opera bajo lo que Freud describió como la identificación de las masas y en las agrupaciones, en tanto es la identificación con la imagen que da al agrupamiento su ideal, a expensas de toda comunicación articulada, y que se constituye alrededor de una tensión hostil (Lacan, 2009, p. 458). Es otras palabras, al privilegiar lo semejante se excluye cualquier rasgo o apariencia de lo diferente, depositando afuera ${ }^{14}$ la amenaza:

13 La distinción entre otro y Otro es central para el pensamiento lacaniano. De forma breve, para Lacan el otro es el otro que no es realmente otro, sino un reflejo y proyección del Yo, por lo que es simultáneamente el semejante y la imagen especular. El Otro designa la alteridad radical, que no puede ser asimilado por la identificación. Lacan equipara esta alteridad con el lenguaje y la ley, de lo que se desprende que el Otro está inscrito en el orden simbólico. Ahora bien, el Otro es lo simbólico en tanto está particularizado para cada sujeto. Así, el Otro es entonces otro sujeto, en su alteridad radical y su singularidad inasimilable, y también el orden simbólico que media la relación con ese otro sujeto. No obstante, el primer significado es secundario respecto del sentido del Otro como orden simbólico, ya que el Otro debe en primer lugar ser considerado un lugar, el lugar donde está constituida la palabra; sólo así es posible hablar del Otro (Evans, 2007, p. 143).

14 Para Freud, esta operación de proyección se constituye desde edades tempranas como una forma de defensa que tiene el yo para defenderse de ciertas excitaciones displacenteras: "Una posterior impulsión a desasir el yo de la masa de sensaciones, vale decir, a reconocer un "afuera", un mundo exterior, es la que proporcionan las frecuentes, múltiples e inevitables sensaciones de dolor y displacer, que el principio de placer, amo irrestricto, ordena cancelar y evitar. Nace la tendencia a segregar del yo todo lo que pueda devenir fuente de un tal displacer, a arrojarlo hacia afuera, a formar un puro yo-placer, al que se le contrapone un ahí-afuera ajeno, amenazador (Freud, 1992c, p. 68). 
"Siempre es posible ligar en el amor a una multitud mayor de seres humanos, con tal que otros queden afuera para manifestarles la agresión" (Freud, 1992c, p. 111).

Por otro lado, la identificación simbólica proviene de la identificación con el significante, con el rasgo unario $^{15}$, con eso que es más que uno: un significante al cual el sujeto se enajena bajo una identificación primera que forma el ideal del yo. Para Lacan, mientras que la estructura del yo descansa en la relación del sujeto con la imagen del semejante, la estructura del ideal del yo plantea un problema específico, es decir, no se constituye como un yo ideal. Por lo tanto, Lacan va a plantear al ideal del yo como algo exterior al sujeto, algo adquirido y que no le pertenece: “... de lo que se llama el Ideal del yo, que resulta ser en adelante una parte del propio sujeto, aunque conserva sin embargo alguna relación con un objeto exterior (...) su Ideal del yo no le pertenece, sin duda, es algo adquirido. No es un objeto, es algo añadido en el sujeto." (Lacan, 1999, p. 297). Proviene de la relación del sujeto con el Otro, en tanto diferencia, se identifica con él precisamente en que es Otro y el sujeto es uno, el sujeto se identifica a partir del deseo, con alguna característica significante o rasgo del Otro, en el orden simbólico:

Lo muestra en el plano de la identificación colectiva, de lo que es en suma una especie de punto de concurso de la experiencia por la que la unaridad del rasgo, si puedo decir, mi rasgo unario - es lo que quería decir - se refleja en la unicidad del modelo tomado como el que funciona en la constitución de ese orden de realidad colectiva que es, si se puede decir, la masa con una cabeza, el líder (Lacan, 1961-1962, p. 680).

Esta depuración que Lacan realiza del planteamiento freudiano, nos introduce a la discusión acerca de cómo el sujeto se posiciona frente a los significantes que provienen del Otro; es decir, cómo el orden simbólico es incorporado y asumido como propio, con qué nos identificamos del mismo. Esta reflexión es de radical importancia para resolver el problema que se ha planteado en este estudio: ¿cómo un conflicto político puede llegar al punto de negar la humanidad del otro, convirtiéndolo en el horror a aniquilar? Dado que si tomamos en consideración lo planteado por Lacan, para que eso sea posible sería necesaria la presencia de un orden simbólico que legitime esta operación. Esto dirige la reflexión sobre qué está pasando con el orden simbólico contemporáneo, qué tipo de significan-

15 A partir del concepto freudiano de rasgo único (Einziger Zug), Lacan desarrolla la noción de rasgo unario como parte de su aparato conceptual destinado a dar cuenta de la identificación. Para el autor, el rasgo unario es el punto concreto en el cual el sujeto ingresa a una identificación inaugural con el significante radical, un significante que actúa como una pequeña diferencia en la constitución del sujeto (Lacan, 1961-1962, p. 18-19). 
tes se están privilegiando para que funcionen como referentes identificatorios que terminan generando violencia sin límites.

En ese sentido, son clarificadores los aportes de Žižek para pensar la identificación y el conflicto político. Žižek (2005, p. 147) plantea que la relación entre la identificación imaginaria y la identificación simbólica es la que hay entre identificación "constituida" y "constitutiva": en términos latos, en la identificación imaginaria nos identificamos con la imagen en la que resultamos amables, que representa "lo que nos gustaría ser"; mientras que en la identificación simbólica es con el lugar desde el que nos observan, desde el que nos miramos de modo que nos resultamos amables, dignos de amor. En la identificación imaginaria imitamos al otro en el nivel de la similitud, en tanto somos como "ellos"; mientras que en la identificación simbólica nos identificamos precisamente en ese punto en el que es inimitable, en el punto que elude la similitud (Žižek, 2005, p. 152).

Ahora bien, aquí es importante incorporar dos precisiones. La primera, es que el rasgo con el cual nos identificamos con alguien o con una idea, habitualmente está oculto $^{16}$. A su vez, este rasgo no es necesariamente una característica encantadora (Žižek, 2005, p. 147), puede ser una cierta falla, debilidad, culpa (Žižek, 2005, p. 148). La segunda precisión, es que ambos mecanismos de identificación están vinculados entre sí:

Pero el segundo error, incluso más grave, es pasar por alto el hecho de que la identificación imaginaria es siempre identificación en nombre de una cierta mirada en el Otro. Así pues, a propósito de cada imitación de una imagen modelo, a propósito de cada "representación de un papel", la pregunta a plantear es: ¿para quién actúa el sujeto este papel? ¿Cuál es la mirada que se tiene en cuenta cuando el sujeto se identifica con una determinada imagen? (Žižek, 2005, p. 148). ${ }^{17}$

Es a partir de esta interacción entre identificación imaginaria y simbólica - bajo el dominio de la última -, que se produce el mecanismo bajo el cual el sujeto se incorpora a un campo socio-simbólico determinado, como se asumen ciertos "mandatos" (Žižek, 2005, p. 153), que le permiten encontrar un "lugar" en la red intersubjetiva de las relaciones simbólicas (Žižek, 2005, p. 156). Esta operación, de la cual no podemos ahondar en detalles, supone una interpelación ideológica y la forma en cómo el sujeto responde a la misma (Pêcheux, 2003), qué tipo de fantasía construye

16 Por esta razón es que la identificación con una ideología cualquiera supone un no-reconocimiento de su falla estructural. Para los sujetos que se identifican con una determinada propuesta ideológica, esta funciona como "una totalidad que borra las huellas de su propia imposibilidad” (Žižek, 2005, p. 81, cursivas en el original).

17 Cursivas en el original. 
para dar respuesta a esa pregunta imposible de qué es lo que quiere el Otro:

La fantasía parece entonces una respuesta al "Che vuoi?", al insoportable enigma del deseo del Otro, de la falta en el Otro, pero es al mismo tiempo la fantasía la que, por así decirlo, proporciona las coordenadas de nuestro deseo - la que construye el marco que nos permite desear algo. La definición usual de fantasía ("un argumento imaginado que representa la realización de un deseo") es por lo tango descarriada, o por lo menos, ambigua: en la escena de la fantasía el deseo no se cumple, no se "satisface", sino que constituye (dados sus objetos y demás) - mediante la fantasía, aprendemos a "cómo desear". En esta posición intermedia está la paradoja de la fantasía: es el marco que coordina nuestro deseo, pero al mismo tiempo es una defensa contra el "Che vuoi?, una pantalla que encubre la brecha, el abismo del deseo del Otro (Žižek, 2005, pp. 162-163). ${ }^{18}$

De esta breve recopilación de los aportes freudianos y lacanianos se pueden extraer tres conclusiones generales. En primer lugar, el sujeto está atravesado por una dependencia estructural, con lo cual, éste no puede ser uno sino a partir de un otro. No hay identidad, sino identificaciones. Esta condición afecta, a su vez, la constitución de las comunidades, las cuales necesitan de un exterior constitutivo para poder adquirir sus límites, mismos que no son permanentes o estables, son móviles y sujetos a la contingencia histórica. Empero, de esto no se deriva una relación necesariamente antagónica. En segundo lugar, se puede entender lo político como una forma de lazo social en dos tiempos: un primer momento que marca la distancia, la diferencia, el límite, que permite distinguir entre el borde interno de la comunidad y su exterioridad; y un segundo momento en el cual esta distinción adquiere un carácter antagónico y existencial. La cuestión de cómo opera este pasaje puede ser resuelta apelando a la relación entre identificación imaginaria e identificación simbólica: la diferencia que el otro encarna se convierte en una amenaza, algo de ese otro lo convirtió en enemigo, amenaza no solo mi comunidad sino a la forma en cómo el sujeto se reconoce a sí mismo. Esto, más allá de las condiciones concretas sobre las cuales se estructura el antagonismo político, toma la estructura de una fantasía, me indica cómo debo desear y qué no debo desear, estructura quiénes deben ser sometidos o quiénes no, quiénes son culpables y quiénes son inocentes. En tercer lugar, un énfasis excesivo en lo semejante obtura la posibilidad de comprender al otro en su diferencia. Tal como veremos más adelante con Derrida, este desplazamiento hacia la mismidad supone el desarrollo de una locura auto-inmune, una vuelta agresiva sobre el sí mismo de la comunidad que supone su auto-destrucción.

A partir de estas tres conclusiones, podemos realizar una reformulación de la

18 Cursivas en el original. 
propuesta original schmittiana. Si lo político es una forma de lazo social que supone una relación antagónica, ésta se apoya sobre la base de una distinción primaria, la cual es la del otro en tanto diferente. La forma precisa bajo la cual se da este pasaje, habría que observarla en el caso por caso, ya que al ser el enemigo una figura necesaria y contingente a la vez, este puede ser cualquiera, siempre y cuando el escenario sobre el cual se dirime una cuestión polémica haya llevado a una intensificación en la distancia entre unos y otros, que ahora se piensan como amigos y enemigos, con la posibilidad concreta y real de darse muerte.

Esta posibilidad supone la presencia de afectos hostiles, y un sacudimiento de la forma que tenía la comunidad hasta el momento. Así, los momentos de antagonismo son aquellos que modifican las coordenadas simbólicas de la representación que tiene la comunidad de sí misma, modificando de forma masiva los mecanismos de identificación y constituyendo así una nueva distribución entre unos y otros, amigos y enemigos. A su vez, esta colisión modifica la forma en cómo el sujeto se percibe a sí mismo, como se identifica en tanto uno y diferencia.

Ahora bien, esta reformulación supone la presencia de un enemigo real como condición necesaria para la representación que tienen las comunidades y los sujetos de sí mismos. Sin embargo, bajo este marco conceptual, ¿cómo pensar los fenómenos a los que Mbembe (2011, p. 20) hace referencia bajo su concepto de necropolítica? La pregunta que se impone es: ¿bajo qué mecanismos de identificación se sostiene un antagonismo que ha desbordado su estatuto político, y que ha impuesto una política de destrucción masiva, que pretende eliminar ese punto de inimitabilidad?

\section{LA FANTASÍA NECROPOLÍTICA}

Para poder contestar lo anterior, es necesario repasar brevemente el argumento de Mbembe en su ensayo Necropolítica (2011). Para este autor, en concordancia con Hobbes y Schmitt, la expresión última de la soberanía reside en el poder de decisión acerca de quién puede vivir y quién debe morir (Mbembe, 2011, 19-20). Este dominio sobre la vida, que había sido conceptualizado por Foucault (1978, 1988, 1990, 2007) como biopoder, supone una administración tecnológica de los cuerpos, que separaba a las personas que deben morir de aquellas que deben vivir, distribuyendo a la especie humana en diversos subgrupos, estableciendo una diferencia biológica entre unos y otros (racismo) (Mbembe, 2011, pp. 23-24).

Sin embargo, el argumento medular del autor (Mbembe 2011, p. 20) es que este concepto ya no es suficiente para entender los eventos contemporáneos, una vez que se observa que la política contemporánea ha desplazado su objetivo de la administración de los cuerpos al asesinato como objetivo primero y absoluto, transformándose en $n e-$ 
cropolítica. En ese sentido, Mbembe parece sugerir que habría un solapamiento entre el biopoder como administración de los cuerpos, y un régimen soberano que ahora no solo decide quién vive y quién muere, sino que muta a una administración que usa la violencia ya no como un medio para lograr rentabilidad, sino como un fin en sí mismo.

Para dar cuenta de las condiciones de posibilidad que permitieron la emergencia de esta apuesta mortífera contemporánea, Mbembe analiza acontecimientos históricos que considera representativos de la relación entre terror y Modernidad. Entre estos, se encuentra el sistema de plantaciones, el mundo colonial y el apartheid, para lo cual enlaza la noción foucaultiana de biopoder, la enemistad y los conceptos de estado de excepción y estado de sitio de Carl Schmitt ${ }^{19}$ (Mbembe, 2011, p. 21).

En ese sentido, apoyado en el trabajo de Foucault Genealogía del racismo (2006), señala que el derecho soberano de matar (droit de glaive) inscrito en el funcionamiento de los Estados modernos, tuvo una aplicación diferenciada en el sistema de plantaciones, el mundo colonial y el apartheid, con respecto a Europa. En estas áreas periféricas, esta función soberana, que para los centros imperiales se reducía al estado de excepción, se convirtió en norma, eran lugares donde el derecho de matar no estaba sometido a ninguna regla (Mbembe, 2011, p. 40).

Así, la estructura del sistema de plantación y sus efectos, reflejan la figura paradójica de un estado de excepción que se hizo norma (Mbembe, 2011, p. 31); en tanto, grupos completos de población fueron reducidos a lo que Mbembe denomina una "muerte social" - una expulsión fuera de la humanidad -. Esta condición era alcanzada a través de una triple pérdida: pérdida del hogar, pérdida de los derechos sobre su cuerpo y pérdida de su estatus político (Mbembe, 2011, pp. 31-32). Si bien se puede argumentar

19 Para Schmitt (2009, p. 15) el "estado de excepción" se define como un concepto general de la doctrina del Estado, no un decreto de cualquier necesidad o un estado de sitio; sino una figura jurídica que regula con precisión los casos en que el derecho se suspende a sí mismo en aras de garantizar la supervivencia del Estado: "El caso excepcional, el que no está previsto en el orden jurídico vigente, puede a lo sumo ser calificado como caso de extrema necesidad, de peligro para la existencia del Estado o de otra manera análoga, pero no se puede delimitar rigurosamente (...) Ni se puede señalar con claridad cuándo un caso es de necesidad, ni cabe tampoco prevenir rigurosamente lo que en tal sazón conviene si el caso de necesidad es realmente extremo y se aspira a dominar la situación" (Schmitt, 2009, p. 16). Para el autor, la excepción es en la jurisprudencia lo que el milagro es en la teología (Schmitt, 2009, p. 37). En el texto La Dictadura, Schmitt (1968, pp. 23-26) define a la dictadura como un estado de excepción necesario. Desde un punto de vista jurídico-político puede significar la supresión del Estado de derecho, que a su vez puede significar diferentes cosas, dependiendo de cómo esté estructurado este. Por ejemplo, en un Estado democrático, la dictadura, en tanto se considera un estado excepción necesario, implica toda violación de principios democráticos o principios liberales a partir de la figura de la excepción. El "estado de sitio" supone la imposición continuada de un régimen de excepción, que lo hace en ocasiones análogo al estado de guerra. Si bien es cierto que estas definiciones no brindan límites precisos para una distinción pura, hay que recordar el estatuto polémico de lo político y su consecuente indeterminabilidad absoluta. 
que a la par de esta muerte social ocurría constantemente una muerte física, es importante para Mbembe dejar claro que bajo este ordenamiento político-económico, el esclavo era propiedad, por lo que se mantiene con vida "(...) pero mutilado en un mundo espectral de horror, crueldad y desacralización intensos” (Mbembe, 2011, p. 33) ${ }^{20}$.

No obstante, continúa Mbembe (2011, p. 35), esta doble inscripción del esclavo, le permitía mantener un mínimo margen de humanidad, podía adoptar puntos de vista diferentes acerca de su vida; lo cual hace que aún siendo un "instrumento" o una "herramienta", podía adquirir una intelección propia: "Tratado como si no existiese más que como simple herramienta e instrumento de producción, el esclavo es, pese a todo, capaz de hacer de un objeto, instrumento, lenguaje o gesto, una representación, estilizándolos" (Mbembe, 2011, p. 34). Este ordenamiento adquirió un carácter más terrorífico en las colonias y en el régimen de apartheid, en las cuales se concatenó el biopoder, el estado de excepción y el estado de sitio, que se articularon alrededor de la noción de raza (Mbembe, 2011, p. 35).

Estas experiencias dirigen a Mbembe al análisis del imaginario europeo, ya que para el filósofo camerunés fue la creencia utópica de una razón sin límites, lo que permitió la emergencia de los diferentes relatos de dominación y emancipación de la Modernidad que operaron a lo interno y a lo externo de Europa ${ }^{21}$ (Mbembe, 2011, p. 28). Un ejemplo paradigmático de esta conjunción entre razón y terror fue la Revolución Francesa, en la cual emergieron dispositivos novedosos de control de población y de aniquilación del enemigo, sobre la base de una diferencia ideológica: "El terror se convierte, por tanto, en una forma de marcar la aberración en el seno del cuerpo político, y lo político es a la vez entendido como la fuerza móvil de la razón y como una tentativa errática de crear un espacio en el que el "error" fuera minimizado, la verdad reforzada y el enemigo eliminado" (Mbembe, 2011, p. 28). Lo anterior trajo como consecuencia que se asociaran los relatos de dominación y emancipación con relatos acerca de la verdad y la muerte, con lo cual el terror y el asesinato se convirtieron en los principales medios sobre los cuales se pretendía llevar a cabo el telos de la Historia (Mbembe, 2011, pp. 30-31).

Ahora bien, más allá de este excurso, es evidente para Mbembe (2011, pp. 36-37) que en el imaginario político europeo, es la colonia el espacio que representa el lugar en el que la soberanía se fundamenta en el ejercicio de un poder al margen de la ley, y donde la "paz" se vivencia como una "guerra sin fin". De esta manera, nos encontramos con un mundo dividido en dos grandes regiones: el orden jurídico europeo - sobre el cual se basa Schmitt para hacer su interpretación -, y el resto del

20 Cursivas en el original.

21 En ese sentido, Mbembe se inscribe en una larga tradición crítica de la Modernidad y sus efectos, que incluye trabajos tales como los de Max Horkheimer y la Crítica a la razón instrumental (1973), Reinhart Koselleck con Crítica y crisis (2007), Gayatri Spivak y la Crítica de la razón poscolonial (2010); entre otros. 
mundo, en el cual la guerra no estaba acotada ni había definiciones convencionales de la enemistad (Mbembe, 2011, p. 39). Lo anterior adquiere particular relevancia, cuando se observa que esta imposibilidad de percibir esta inadecuación es tal, que si bien el propio Schmitt da cuenta de las líneas de amistad que dividían al mundo en la Modernidad y que tuvieron por consecuencia un ejercicio de violencia sin límites, no logra incorporar esta experiencia histórica dentro de su teoría. Tal como se planteó previamente, Schmitt parece perplejo frente a lo que denomina "nuevas formas de enemistad", sin reconocer que las mismas tenían su condición de posibilidad en el nomos de la tierra creado por las potencias europeas en la Modernidad:

En esta línea terminaba Europa y comenzaba el Nuevo Mundo. Aquí terminaba el Derecho europeo, en todo caso el Derecho público europeo. En consecuencia, también terminaba aquí la acotación de la guerra conseguida por el Derecho de Gentes europeo y comenzaba la lucha desenfrenada en torno a la toma de la tierra. Más allá de la línea comienza una zona "ultramarina" en la que, por faltar toda barrera jurídica de la guerra, solo rige el derecho del más fuerte. (...) Lo único en lo que están prácticamente de acuerdo los partenaires de tales relaciones es la libertad de los nuevos espacios que comienzan al otro lado de la línea. La libertad consiste en que la línea delimita una zona de aplicación libre y desconsiderada de la violencia. (...) De aquí tenía que surgir necesariamente la idea general de que todo lo que sucede "más allá de la línea" queda también fuera de las valoraciones jurídicas, morales y políticas que están reconocidas a este lado de la línea (Schmitt, 2005, p. 77).

Por esta razón, la sorpresa y preocupación del jurista alemán frente a lo que denominó la destrucción de las estructuras sociales (Schmitt, 1966, p. 102) y el desdibujamiento del concepto de enemigo posterior a la I Guerra Mundial (2009b, p. 136), lo que muestran es la incapacidad del mundo europeo de reconocer las consecuencias simbólicas que se derivaron del mantenimiento de un orden político sustentado en una enemistad absoluta ${ }^{22}$.

$22 \quad$ Se podría objetar que al mantener vivo al esclavo no se estaba recurriendo a una guerra de aniquilación, pero hay que recodar que para Schmitt la enemistad absoluta refiere a la estructura de posibilidades que permite la deshumanización del otro y que lo convierten en un horror humano a aniquilar. En ese caso, esa estructura se expresaba a través de una muerte-en-vida y a su vez, en el desprecio masivo al dolor y sufrimiento humano que conllevaba la explotación. Además, no se puede negar que esta condición de despojo incidía en que la mortalidad de las personas esclavizadas era mucho mayor que para la población dominante: "El terror colonial se entremezcla más bien incesantemente con un imaginario colonialista de tierras salvajes y de muerte y con ficciones que crean la ilusión de lo real. La paz no constituye necesariamente la consecuencia natural de una guerra colonial. De hecho, la distinción entre guerra y paz no resulta pertinente. Las guerras coloniales se conciben como la expresión de una hostilidad absoluta, que coloca al conquistador frente a un enemigo absoluto. Todas las manifestaciones de guerra y hostilidad convertidas en marginales por el imaginario legal europeo encuentran en las colonias un lugar 
Fue hasta el arribo del Estado nazi que esta operación simbólica se hizo evidente a la mirada del mundo europeo, producto del desplazamiento del locus de ejercicio de la autoridad soberana de una alteridad concebida como algo circunscrito a un territorio otro, a una alteridad que coexistía en el mismo espacio. En otras palabras, fue hasta que estas líneas de amistad se "difuminaron" - ya se señaló previamente que tampoco fue que el territorio europeo estuvo exento de guerras de aniquilación -, que la pregunta por el Otro, en tanto alteridad, se impuso como una urgencia.

De esta breve exposición se extraen dos puntos. En primer lugar, la colonia se gestó sobre la fantasía de que la razón podía organizar el mundo, sobre la base de una enemistad absoluta que hizo de los seres humanos dominados cosas, $o b$ jetos; los expuso a una "muerte-en-la-vida" (Mbembe, 2011, p. 33), anulándolos como sujetos, aunque conservando su lugar de Otro como alteridad radical: "La soberanía significa ocupación, y la ocupación significa relegar a los colonizados a una tercera zona, entre el estatuto del sujeto y del objeto" (Mbembe, 2011, p. 43). Esta ambigüedad permitió que se sostuviera al Otro como punto de frontera, mantuvo la posibilidad de subjetivarse a partir de no ser ese Otro. En segundo lugar, esta forma de dominación basculó de las colonias a Europa, un retorno que estuvo caracterizado no solo por esta forma de racionalización, sino por el perfeccionamiento de las tácticas y herramientas de destrucción del Otro:

Por una extrapolación biológica del tema del enemigo político, al organizar la guerra contra sus adversarios y exponer también a sus propios ciudadanos a la guerra, el Estado nazi se conceptúa como aquel que abrió la vía a una tremenda consolidación del derecho de matar, que culminó en el proyecto de la "solución final". De esta forma, se convirtió en el arquetipo de una formación de poder que combinaba las características del Estado racista, el Estado mortífero y el Estado suicida (Mbembe, 2011, pp. 23-24).

Hasta este punto, Mbembe abre el análisis a puntos inexplorados por el pensamiento schmittiano, señalando la responsabilidad europea en la destrucción y sufrimiento de territorios bajo la ocupación colonial. Empero, eso no impide que arribe a una preocupación similar. Si para Schmitt en $1963^{23}$, la preocupación era que se había desbordado la enemistad y que estábamos arribando a un escenario de auto-destrucción; para Mbembe, cuarenta años después, la política contemporánea ha hecho de la violencia un fin en sí mismo, del asesinato su objetivo último: se ha convertido en necropolítica. No obstante, como se verá más adelante, este punto

para emerger de nuevo. Aquí, la ficción entre una distinción entre "fines de guerra" y "medios de guerra" se desmorona, al igual que la idea según la cual la guerra funciona como un enfrentamiento sometido a reglas, oponiéndose a la masacre pura, sin riesgo o justificación instrumental" (Mbembe, 2011, p. 41).

23 Fecha de la publicación alemana de Teoría del partisano. 
es polémico en tanto Mbembe no logra demostrar con claridad este concepto, ya que los ejemplos que brinda para sustentar lo anterior pueden ser calificados como escenarios en los cuales las condiciones de posibilidad del terror previas han sido intensificadas y/o agudizadas por la presencia de una tecnología de vigilancia y de aniquilación más efectiva y de menor costo; referencia que ya se puede encontrar en Schmitt cuando apunta hacia las "armas supraconvencionales".

Pero antes de avanzar sobre esta crítica, veamos las características que para Mbembe diferencian la ocupación colonial tardía, tal como él la denomina (Mbembe, 2011, p. 42-53). El punto de contraste estaría en que, en el marco de las guerras imperiales, el objetivo era la destrucción de los poderes locales, la instalación de tropas y la instauración de nuevos modelos de control militar sobre la población civil; en consecuencia, la violencia sería la forma original del derecho y la estructura de la soberanía está proporcionada por la excepción (Mbembe, 2011, p. 42). Por su parte, la ocupación colonial de la modernidad tardía está atravesada por un encadenamiento entre tres tipos de poder: el disciplinario, el biopolítico y el necropolítico; con lo cual, el objetivo del ejercicio soberano son poblaciones enteras, los pueblos y ciudades se cercan, se amputan del mundo, y se militariza la vida cotidiana (Mbembe, 2011, pp. 52-53).

Como ejemplo paradigmático de lo anterior, Mbembe (2011, pp. 46-47) toma el caso de la ocupación colonial en Palestina. En este territorio, la ocupación se legitima sobre la base de un relato histórico particular que identifica el territorio ocupado con un designio divino y un principio de identidad que se desprende del mismo. A esto se le suma el requisito de que las poblaciones en litigio no se encuentran separadas geográficamente, sino que coexisten en un mismo territorio, lo que hace que la ocupación tome otras formas. Es decir, Mbembe (2011, p. 45) coincide con Fanon (1999, p. 29) cuando éste plantea que la ocupación colonial del pasado implicó una división del espacio en compartimentos, a partir del despliegue de límites y fronteras internas, fundada sobre un principio de exclusividad recíproca; fenómeno que en el caso de la ocupación palestina es más complejo y difuso.

A partir de lo anterior, Mbembe señala que existen tres características principales de la formación específica de terror que denomina "necropoder": la primera, una dinámica de fragmentación territorial, el acceso prohibido a ciertas zonas y la expansión de las colonias, dividiendo a los territorios en una red compleja de fronteras interiores y de células aisladas (2011, pp. 47-48). Esto implica la presencia de una vigilancia que está orientada hacia el exterior como al interior (2011, p. 49). En segundo lugar, la forma fragmentaria de ocupación colonial se caracteriza por una infraestructura que se gesta con el objetivo de mantener la “exclusividad recíproca", procurando que las redes viarias israelís y palestinas, no se crucen nunca (2011, p. 50). Esto nos dirige a la última característica, la cual es la 
proliferación de los espacios de violencia, campos de batalla múltiples y altamente tecnologizados: "Matar se convierte en un asunto de alta precisión" (Mbembe, 2011, p. 51). Esto supone para Mbembe un "estado de sitio" (2011, p. 52-53), en el cual la posibilidad de dar-muerte se traslada del soberano a sus representantes en el terreno: ejércitos, policía, máquinas de guerra (Mbembe, 2011, pp. 58-59).

Esto lo lleva a concluir que existe una forma de gubernamentalidad colonial diferente del mando colonial del pasado:

Esta forma de gubernamentalidad difiere del mando colonial. Las técnicas de la autoridad policial y de disciplina, la elección entre obediencia y simulación que caracteriza el potentado colonial y postcolonial se sustituyen gradualmente por una alternativa más trágica, dado su extremismo. Las tecnologías de destrucción son ahora más táctiles, más anatómicas y sensoriales, en un contexto en el que se decide entre la vida y la muerte. Si el poder depende siempre de un estrecho control sobre los cuerpos (o sobre su concentración en campos), las nuevas tecnologías de destrucción no se ven tan afectadas por el hecho de inscribir los cuerpos en el interior de aparatos disciplinarios como por inscribirlos, llegado el momento, en el orden la economía máxima, representado hoy por la "masacre" (Mbembe, 2011, p. 63).

Ahora bien, hasta el momento Mbembe describe una situación de violencia sin límites que no se diferencia más que en la extensión y uso de tecnología, con respecto a los escenarios previos que él mismo analiza. Por ejemplo, la coexistencia de poblaciones en un mismo espacio es algo que se puede constatar en territorios que subsisten a partir de economías de enclave - las repúblicas bananeras centroamericanas -, en países con poblaciones segregadas - Estados Unidos o Sudáfrica son ejemplos claros -, o inclusive a partir de un manejo del espacio público que genera prohibiciones tácitas de tránsito en una misma comunidad. Es decir, inclusive en el análisis del atentado suicida (Mbembe, 2011, pp. 65-71), la presencia histórica del kamikaze no sería una novedad, ya que fue una práctica, que como su propio nombre indica, propia de las tácticas utilizadas por el ejército japonés en la II Guerra Mundial.

Por tanto, ¿dónde está lo nuevo en esta apuesta necropolítica, cuando los ejemplos que Mbembe utiliza para sustentar su interpretación pueden ser rastreables a lo largo de la historia como efectos inmanentes a la deshumanización? ¿Acaso no está Mbembe tomando como "nuevo" lo que en realidad es un agudizamiento de las condiciones de posibilidad gestadas en la Modernidad? En ese sentido, tres precisiones. En primer lugar, una vez que se asume el supuesto de que en todo lazo social político la muerte es una posibilidad, 
el prefijo necro pierde su distinción, ya que toda relación política estaría atravesada por esa posibilidad. En segundo lugar, si lo que quiere Mbembe es referirse a los contextos donde hay una violencia sin límites, rastreando cómo la enemistad absoluta es escenificada en la política contemporánea, tiene que reconocer que esta posibilidad está inscrita desde el momento en el cual hay conflicto político. Esto no quiere decir que el aporte de Mbembe sea irrelevante, al contrario, logra acuñar un concepto que permite visibilizar esa zona que Schmitt observaba más allá de la política, en la cual la espiral mortífera puede alcanzar niveles incontenibles. Finalmente, el criterio acerca de que la violencia se ha convertido en un fin en sí mismo no es demostrado con claridad, ya que si bien en el caso Palestino lo que priva es el imaginario israelita de ser "el pueblo escogido por Dios", no es el único caso en el cual se invocan razones de corte religioso, ideológico o inclusive metafísico para aniquilar otras poblaciones; el mismo Mbembe lo indica cuando se refiere a la Revolución Francesa. En ese sentido, parece ser que Mbembe identifica la "rentabilidad" de la violencia con un objetivo económico claro: en una economía esclavista y/o de plantación, al menos se mantenía con "vida" al esclavo en tanto mano de obra; mientras que la ocupación israelita en Palestina no parece tener más objetivo que la aplicación de la violencia como un fin en sí mismo. En este punto Mbembe parece caer en una lectura económica de la violencia, sin preguntarse qué ganancias simbólicas podrían estar recibiendo los israelitas a través de este escenario de deshumanización, a qué estatuto aspiran a través de una política sistemática de exterminio del Otro.

En este punto es evidente que Mbembe encuentra dificultades para distinguir los efectos recrudecidos del biopoder, tal como lo conceptualizó Foucault, y lo que él quiere indicar como una nueva forma de gubernamentalidad. Bajo esta línea, el enemigo que aparece en una configuración necropolítica no es más que el enemigo absoluto schmittiano. No obstante, eso no quiere decir que su puntualización no sea pertinente. Mbembe, al igual que Schmitt, observa con detalle y preocupación la proliferación de escenarios de violencia; aunque, al igual que el jurista alemán, no ahonda en qué está pasando con respecto a la subjetividad que permite la presencia cada más frecuente de este tipo de ordenamientos políticos. Es decir, no se pregunta qué está pasando con el lazo social, que transita de forma cada vez más fácil hacia escenarios de deshumanización.

Para responder lo anterior, a modo de cierre, propongo una lectura que incorpore el psicoanálisis lacaniano a la discusión, tratando de dar una interpretación que permita entender los escenarios contemporáneos, y a la vez, dar cuenta de esas lagunas interpretativas en ambos autores.

\section{LA METONIMIA DE LA DESTRUCCIÓN}


Una vez que se ha establecido que el enemigo en la necropolítica puede ser leído conceptualmente a través de la noción de enemigo absoluto, la pregunta que queda por resolver es bajo qué mecanismos de identificación opera este pasaje, de un enemigo real o convencional a un enemigo que se observa como inhumano y aniquilable.

Antes de avanzar, es importante realizar una precisión teórica-conceptual. Si bien cuando se trabaja sobre las distinciones de nosotros y ellos, o amigos y enemigos, se tiende a reducir formalmente el planteamiento a una relación de espejo - en tanto el enfrentamiento de dos unidades diferenciadas -; en la práctica política, lo que se observa es una conjunción y sobredeterminación de estas oposiciones. Esta aclaración es de radical importancia una vez que se observa que hay múltiples comunidades de amigos y múltiples comunidades de enemigos, que en su contingencia radical mutan, se movilizan, y se transforman. Por ello, antes que caer en las aporías que se desprenderían de una metáfora especular, se podría pensar en una metáfora fractal-especular. En otras palabras, múltiples puntos de reflexión bajo los cuales los sujetos se miran, se identifican o se des-identifican.

En consecuencia, cuando previamente se planteó a lo político como una forma de lazo social, y a la comunidad política como un resultado contingente de un conflicto necesario, nos estamos refiriendo a una relación entre dos grupos humanos o más, con lo cual cada análisis concreto debe ser abordado de forma particular. Lo mismo aplica para pensar ese primer momento discrecional de construcción de la comunidad, que se desprende de una primera línea de frontera establecida a partir de la distinción entre nosotros y ellos.

Ahora bien, realizada esta aclaración, queda por resolver el problema del pasaje a la enemistad absoluta. Tal como se ha planteado, de acuerdo con Freud y Lacan no hay uno sin un Otro, así como no hay comunidad de nosotros sin un ellos. No es posible la subjetividad ni el lazo social sin un exterior constitutivo. De igual manera, Schmitt sospechaba de los efectos destructivos que implica la eliminación del enemigo como exterior constitutivo. Por tanto, la pregunta que se impone es qué está pasando con el orden político contemporáneo para que se recrudezcan los escenarios autodestructivos.

Derrida (1998) en Políticas de la amistad brinda elementos para dar esta discusión, a partir de dos supuestos. El primero, en línea con lo dicho previamente, que el amigo y el enemigo se co-determinan, y esta correlación puede seguir tres vías lógicas. Aquí la impronta del pensamiento schmittiano y freudiano es evidente: no se puede disociar la amistad de la existencia, no se puede disociar la experiencia de la amancia sin su mortalidad inmanente. En la primera de ellas, derivada del contenido existencial de la relación, Derrida interpreta que no se puede hablar de amigos sin contemplar esa posibilidad de dar muerte que instaura una co- 
munidad no natural: "Amar con amor o con amistad significaría siempre: puedo matarte, puedes matarme, podemos matarnos. Juntos, o el uno al otro, la una a la otra". (Derrida, 1998, p. 144). Derrida enfatiza acá en la igualdad de los seres humanos a partir de la mortalidad, a partir de la posibilidad siempre presente de la muerte.

En segundo lugar, esta posibilidad de dar muerte, tiene por consecuencia que para poder hablar de los amigos, se tenga que contemplar la suspensión de esa posibilidad:

La amistad consistiría en suspender esta estructura de posibilidad... sería justamente lo contrario del dar muerte, de esa apuesta de muerte, de esa apuesta mortífera, incluso si, como recuerda Freud, el «no matarás» más categórico, más incondicional, confirma y en consecuencia dice la posibilidad real que la prohibición ordena interrumpir diciéndola (Derrida, 1998: 144).

Como tercera y última interpretación lógica, Derrida entonces plantea que lo que liga u opone sin fin a la pareja amigo/enemigo, en esta apuesta de muerte, sería lo político (Derrida, 1998, p. 144). Por lo tanto, al no poder existir hostilidad sin la posibilidad real de dar muerte, no hay tampoco correlativamente amistad fuera de esa pulsión de muerte (Derrida, 1998, p. 145-146). En este punto Derrida se acerca bastante a Freud. Lo que liga u opone al ser humano es la agresividad que se suspende o se ejecuta.

Sin embargo, Derrida no se queda en enunciar estas tres posibles interpretaciones lógicas. Este es el segundo supuesto. Ninguna de éstas por sí misma es capaz de explicar esa condición que liga al amigo y al enemigo, ninguna puede dar la palabra final que explique la relación amigo/enemigo: “Así, pues, nos hace falta tener paciencia en la encrucijada y soportar esta indecidible trivialidad. Sin la cual, ésta es la tesis y la decisión, ninguna decisión sería posible, ni jamás amistad alguna." (Derrida, 1998, p. 144). No nos dice por qué nos hacemos exactamente amigos o enemigos, sino que refleja una ley: la ley del acontecimiento, la excepción es la regla, es la posibilidad real de su posibilidad real (Derrida, 1994/1998: 150).

Lo peligroso, por tanto, no consistiría en esta indeterminación, sino en obviar esta apertura fundamental e intentar reducir este movimiento constante hacia una realidad demasiado fijada. La pretensión de un mundo sin enemigos solamente llevaría a un mundo sin amigos, a un mundo sin distinción, en el cual la locura auto-inmune llevaría a los sujetos en cuestión a buscar nuevas enemistades reconstituyentes, multiplicaría las "pequeñas guerras", alimentaría a todo precio las tentativas identitarias y genocidas (Derrida, 1998, p. 95). No reconocer esta condición inmanente a la humanidad solamente llevaría a la exclusión de sectores de la humanidad, que por no comprometerse al modelo homogéneo de la amistad, serían ubicados como fuera-de-la-humanidad, con lo cual ya no se au- 
toriza su combate, sino su aniquilación.

Con base en estos dos supuestos, podemos brindar una aproximación al problema en cuestión, ya que pareciera ser que los temores de Schmitt, Derrida y Mbembe se están cumpliendo. Estamos asistiendo a múltiples escenarios de violencia desbordada y de indiferencia general. Es decir, por más que haya voces que clamen en contra de la muerte de los migrantes en el Mediterráneo y en otras partes del globo, sectores que alertan contra el aumento de la xenofobia, de las políticas de extrema-derecha, contra el aumento de los fundamentalismos de toda índole; pareciera ser que las condiciones empeoran inexorablemente.

En ese sentido, si hay algo que articula a Schmitt, Derrida y Mbembe fue haber señalado la continuidad que existía entre el pensamiento moderno europeo, su énfasis en la razón y la construcción de la otredad radical, con la aparición de formas de exterminio más efectivas y rápidas. Sin embargo, paralelo a esto, estos autores observan con preocupación una ruptura, algo que no terminan de comprender, pero que los lleva a señalar que tal vez estemos asistiendo a un punto inédito en la historia, no solo por la presencia de una tecnología que podría acabar con la vida en el planeta en pocos minutos; sino porque pareciera ser que la diferencia se percibe cada vez más como algo que amenaza la constitución del sujeto, y no como aquello que permite su emergencia.

La pregunta que asoma es si esta ruptura supone algo radicalmente distinto; ya que ha habido otros momentos históricos en los cuales la defensa de la vida no ha sido un valor inalienable. No obstante, aún si observáramos en los acontecimientos contemporáneos el retorno de formas de ejercicio de violencia que se creyeron superadas, es sobre la base de esa racionalidad que emergería lo novedoso. En otras palabras, ya existe en el registro simbólico la posibilidad de invocar que se está cometiendo un daño, ya que fue el pensamiento moderno el que permitió una acotación de la guerra, al menos en el imaginario europeo.

Esto nos dirige a otro asunto, de mayor alcance y de la cual aquí apenas se esboza la inquietud, la cual es la pregunta por la Modernidad y sus efectos, ya que es un lugar común en las humanidades y en las ciencias sociales plantear el pasaje del mundo pre-moderno al Moderno como un punto de inflexión humano, como una mutación del orden simbólico en su totalidad. Sin embargo, es claro que el proyecto moderno se hizo a costa de las colonias y que sus efectos/beneficios no fueron distribuidos en el globo; sino que mayoritariamente se concentraron sus avances en los países que formaban parte de los proyectos imperiales. Además, la división entre periodos históricos nunca será un parte-aguas radical, y que claramente lo que se denominó Modernidad arrastró de forma sedimentada componentes de la pre-modernidad. No obstante, esto no impidió que se fijara la idea de que 
había formas de conflicto político ya superadas, como sí hubiéramos alcanzado un piso del cual nunca más podríamos bajar, con lo cual se descuidó la persistencia de estos restos y la emergencia de nuevas formas de enemistad. Así, pareciera ser que los imaginarios modernos que sustentaron buena parte de la reflexión política contemporánea han colapsado, condición que permite comprender la vacilación conceptual y las ambigüedades que hemos señalado en Schmitt y Mbembe para dar cuenta de la condición contemporánea. Empero, resolver lo anterior supondría otro texto. Por el momento basta con señalar esta línea de fuga.

Retornemos al psicoanálisis. Tal como se planteó previamente, para que un Otro como alteridad radical pueda ser nombrado se necesita de un orden simbólico que permita hablar del Otro. Esto tiene por consecuencia que el sujeto es hablado por el orden simbólico, es decir, que estamos sujetos a las palabras del Otro. Frente a esto, nos encontramos en un escenario aparentemente contradictorio. Por un lado, un aceleración y comprensión espacial-temporal que abre el espectro de la diferencia, de lo múltiple. Por otro lado, un retorno de formas cerradas de interpretar la diferencia, una búsqueda del cierre alrededor del Uno, de algo que organice y fije de forma definitiva esta multiplicidad. Lo que parece estar imperando es una rigidización del sentido. Ejemplos de lo anterior abundan: discursos anti-ciencia -terraplanistas, antivacunas -, fundamentalismos religiosos, el auge de la extrema derecha, la dificultad de articulación que tienen los sectores de izquierda, el rechazo a propuestas de pensamiento que introduzcan la reflexión y no la certeza matemática, entre muchos otros más.

A esto se le suma, la "victoria" del pensamiento único, la conjunción entre democracia liberal- procedimental y capitalismo, que llevó a algunos autores a pensar en el "fin de la historia" (Fukuyama, 1989). Esto tuvo por consecuencia que se hegemonizara un modelo de democracia que pretende tramitar el conflicto a través de un aparato jurídico basado en la defensa de los derechos civiles y políticos de primera generación; y por medio de procedimientos electorales que canalizaran las demandas políticas y sociales. El resultado de lo anterior es un modelo democrático que anula o elimina la posibilidad del disenso, a través de la pretensión de que todo aquello que ocasione una demanda política debe ser resuelto vía institucional. Esto no quiere decir que la democracia liberal-procedimental prohíba la manifestación popular, pero tiende a darle legitimidad solamente si se presenta como parte de un actor institucionalizado - partidos políticos, cabilderos, organizaciones no-gubernamentales, etc. -. En consecuencia, aquellos movimientos que operan fuera de la esfera electoral se enfrentan a una encrucijada: o mutar e ingresar en el juego de las preferencias electorales, constituyéndose como partido político o aliándose a uno; u operar en la periferia y arriesgarse a ser invisibilizados o perseguidos por las fuerzas del Estado, en tanto se ubican como enemigos a esta definición de democracia 
(Álvarez Garro 2013, pp. 180-181).

Aunado a lo anterior, los partidos políticos han fracaso en la representación de las demandas de la comunidad y, por ende, han dejado de ser referentes identificatorios para la ciudadanía. Este movimiento, que ha sido denominado por Manin (1998) como el paso de la democracia de partidos a la democracia de mercado, se caracteriza por la desaparición de los referentes ideológicos - aquí entendiendo ideología como haz de ideas históricas - que caracterizaron a los partidos políticos, desde mediados del siglo XIX, hasta finales de la década de 1970; momento en el cual los partidos se convierten en maquinarias "atrapa-todo", sin distinciones claras entre sí, y por ende, sujetos a las identificaciones volátiles que posibilita un determinado o determinada candidata en la población. En resumido, Manin lo que alerta es que ya no se vota por un partido, sino por una persona - rasgo que usualmente se piensa solo dentro del populismo, pero que es propio de las democracias de audiencias -. A este debilitamiento de la administración política, se le añade, el hecho de que los sectores críticos de la sociedad tienen serias dificultades para poder crear espacios de articulación y de formas novedosas de enfrentarse a la dominación; otro ejemplo de los cierres de sentido que parecen imperar en la sociedad. La victoria del pensamiento único solo ha llevado a una proliferación de mundos fragmentados: sujetos y/o asociaciones que no están dispuestas a ceder en sus imaginarios y que se sostienen de forma antagónica.

En el terreno económico también nos estamos enfrentando a un escenario límite. Las consecuencias nefastas que ha introducido el modelo económico neoliberal comienzan a ser evidentes en cualquier parte del globo. El aumento en la desigualdad económica, la incapacidad de pensar un modelo distribuido y la forma en cómo esto ha impactado en la subjetividad, es un tema que requiere ser trabajado con mayor detalle. Sin embargo, eso no impide brindar unas puntualizaciones. Foucault (2007) fue uno de los primeros en alertar que el neoliberalismo introducía profundas modificaciones en la manera en cómo los sujetos respondían frente a la interpelación ideológica. Así, cada sujeto debía ser empresario de sí mismo, asimilando cada área de su vida bajo la idea de forma-empresa (Foucault, 2007, pp. 264; 278); en la cual el otro siempre es un competidor. De esta manera, se instala una lógica en la cual hay una constante disputa por los recursos, bajo el signo de una vigilancia, una actividad, una intervención permanente (Foucault, 2007, p. 179). Esto traslada la responsabilidad del "éxito" y la "eficiencia" en el manejo de los recursos a los sujetos, dado que el neoliberalismo deposita las responsabilidades del malestar contemporáneo en el sujeto, con lo cual la salida inmediata de este sujeto es culpar al otro especular.

De este modo, mientras que la democracia se ha reducido a un procedimiento que no incentiva la creación de lazo social, y el capitalismo neoliberal deposita 
en el sujeto la absoluta responsabilidad de su futuro; no se puede esperar otro resultado que no sean el crecimiento cada vez mayor de sujetos y agrupaciones que prefieren descargar su frustración en el otro, antes que en un orden político y económico que les cierra las posibilidades de expresión, resistencia y emancipación.

Ahora, antes de caer en un análisis precipitado que deposite en una estructura las condiciones de posibilidad de este orden simbólico, hay que recordar que para el psicoanálisis freudiano y lacaniano, no hay un límite estricto entre el exterior y el interior. Así como el sujeto es hablado por el orden simbólico, también participa de su constitución. Por consiguiente, no solo estamos frente a la presencia cada vez más desbordada de discursos que invocan al Uno - religioso, económico, moral, etc- -, sino frente a sujetos que lo demandan. Es decir, por una parte estamos frente a los mandatos que se articulan a partir de la forma particular en que cada uno de nosotros nos identificamos imaginariamente y simbólicamente con ciertos discursos; y por otra parte, la forma en cómo estructuramos nuestro deseo con relación al Otro.

Dicho de otro modo, habría que analizar con detalle los efectos que ha tenido este campo socio-simbólico determinado en la constitución de la fantasía del sujeto, como el capitalismo tardío presiona sobre la fantasía: ¿qué tipo de fantasías impulsa el neoliberalismo? ¿cómo resuelven los sujetos el mandato de ser "exitoso" y "efectivo" bajo condiciones de precariedad económica y social? ¿Qué siente el sujeto que espera el Otro y el otro? ¿Qué papel está llamado a cumplir?

En esta conjunción pareciera crearse una apuesta mortífera: sujetos que prefieren identificarse con discursos de certeza en los cuales se ubica como amenaza principal a aquello que haga diferencia, con un deseo en el que parece imperar la pulsión de muerte antes que la creación de vínculos. En otras palabras, cada vez hay mayores dificultades para pensar al Otro como alteridad que me constituye, que es productiva; en su lugar, aparecen discursos que solo ubican al Otro como amenaza, como alguien que ya ni tan siquiera merece ser considerado humano y, por ende, no funciona como enemigo real y es necesario su aniquilamiento. Es un orden simbólico que crea condiciones de posibilidad para su propio devoramiento a partir de una fantasía necropolítica: para existir debo aniquilar.

Claramente, si asumimos que los enemigos son múltiples, todavía resta tiempo para llegar un punto de confrontación final, si se pudiera decir algo así. No obstante, el asunto es que esta violencia sin límites parece ir cerrando el círculo. La espiral está en un proceso de aceleración centrípeta: se deshumanizan a todos aquellos que no compartan mi mismidad: odio al migrante, odio a las mujeres, odio a las personas sexualmente marginalizadas, y así sucesivamente; hasta que ya no quede punto de proyección de la agresividad. Si a eso le sumamos la presencia de mayores medios de aniquilación en conjunción con la comprensión 
espacial-temporal, podemos pensar que estamos a las puertas de mayores niveles de conflictividad, así como de mayores dificultades para producir lazo social.

\section{CONCLUSIONES}

A manera de cierre, me parece importante destacar dos cosas. La primera, es que encontrar el punto de quiebre en el cual se dio inicio a esta configuración sería un despropósito. Esto porque el orden simbólico y las distintas configuraciones de lo político se solapan no solo entre sí, sino que están sobredeterminados. Lo que estamos observando es el resultado de la acumulación histórica de una serie de contingencias políticas, sociales y económicas. No podemos ubicar con precisión - y eso sería una apuesta de una teoría fundamentada - un arkhé ni un telos a la historia. Lo que se puede hacer es una lectura del juego en el que estamos situados, trazando líneas de perspectiva histórica, pero sin pretender con esto dar una respuesta que detenga la interpretación. Pretender lo contrario nos ubicaría exactamente en aquello a lo que estamos criticando. La segunda, es que contextos de incertidumbre exacerbada son caldo de cultivo para este tipo de construcción imaginaria. Sin oportunidades sociales ni económicas la pregunta por qué quiere de mí el Otro se vuelve demasiado insoportable. Retorna el fantasma del Uno, de una persona o una idea que vuelva a readecuar los indicadores de certeza, fijando posiciones o lugares; que elimine la apertura, reinstale un orden "incorruptible", con los cuales los sujetos parecieran ser devueltos al mar de la tranquilidad. Aparece como posibilidad "el extraño deslizamiento que se opera entre no darse a nadie - que es la fórmula misma de la libertad - darse a algo que es como uno mismo, y reencadenarse a un poder impersonal y sin límite, en el sentido de que ya no es el de Otro (Lefort, 1990, p. 192). Es en este punto donde un discurso que cierre el juego de las diferencias y abogue por una única visión de mundo se vuelve profundamente tentador - y no solo dentro del conservadurismo, sino dentro de los mismos sectores progresistas, que terminan defendiendo un esencialismo de lo particular -. Por consiguiente, de lo que se trata es de asumir la incertidumbre y plantearse otras formas de convivencia, otros significantes y otros discursos que permitan salir de esta metonimia de la destrucción, que permitan suspender esta apuesta mortífera a través de lo político.

Eliminar la distinción entre amigos y enemigos conllevaría el desarrollo de una espiral metonímica que persigue la diferencia, fundamentada en la defensa de una noción de sociedad y de ser humano que solo busca imponerse como la verdadera. Así, la comunidad política de "solo amigos" guardaría tanto recelo frente a aquellos que quizá no se ubiquen en la misma, que solo generaría una violencia sin límites.

\section{FUENTES CONSULTADAS}


Álvarez Garro, L. (2013). La democracia liberal-procedimental. Un análisis del concepto desde la teoría posfundacional. Tesis para optar por el Grado de Doctora en Humanidades con énfasis en Filosofía Moral y Política. México: Universidad Autónoma Metropolitana.

Arditi, B. (2012). Sobre lo político: Schmitt contra Schmitt. Revista de El Colegio de San Luis, Nueva Época. II (3), 11-41.

Derrida, J. (1998). Políticas de la amistad. Madrid: Editorial Trotta.

Evans, D. (2007). Diccionario introductorio de psicoanálisis lacaniano. Buenos Aires: Paidós.

Foucault, M. (1978). La "gubernamentalidad”. En: Giorgi, G. \& Rodríguez, F. (2007). Ensayos sobre biopolitica. Excesos de vida. Buenos Aires, Argentina: Paidós.

Foucault, M. (1988). El sujeto y el poder. Revista Mexicana de Sociología. 50 (3), 3-20.

Foucault, M. (1990). Tecnologías del yo. España: Paidós.

Foucault, M. (2006). Genealogía del racismo. La Plata, Argentina: Editorial Altamira.

Foucault, M. (2007). Nacimiento de la biopolítica. Argentina: FCE.

Freud, S. (1992a). Más allá del principio del placer. Obras completas. Tomo XVIII. Buenos Aires, Argentina: Amorrortu.

Freud, S. (1992b). Psicología de las masas y análisis del yo. Obras completas. Tomo XVIII. Buenos Aires, Argentina: Amorrortu.

Freud, S. (1992c). El malestar en la cultura. Obras completas. Tomo XXII. Buenos Aires, Argentina: Amorrortu.

Fukuyama, Francis. 1989. "El fin de la historia". En: Fukuyama, Francis. (s.f.). Fin de la historia y otros escritos, 3-19. Versión digital. Recuperado el 6 de febrero de 2017 del sitio http://firgoa.usc.es/drupal/files/Francis\%20 Fukuyama\%20-\%20Fin\%20de\%201a\%20historia\%20y\%20otros\%20 escritos.pdf

Horkheimer, M. (1973). Crítica de la razón instrumental. Buenos Aires: Editorial Sur.

Koselleck, R. (2007). Crítica y crisis: un estudio sobre la patogénesis del mundo burgués. España: Editorial Trotta

Koselleck, R. (2012). Historias de conceptos. Estudios sobre semántica y pragmática del lenguaje político y social. Madrid, España: Editorial Trotta.

Lacan, J. (1961-1962). Seminario 9. La identificación. Versión crítica de Ricardo E. Rodríguez Ponte. Buenos Aires, Argentina: Escuela freudiana de Buenos 
Aires.

Lacan, J. (1999). Seminario 5. Las formaciones del inconsciente. 1957 - 1958. Barcelona: Paidós.

Lacan, J. (2009). Escritos I. México: Siglo XXI Editores.

Laclau, E. (2005). La razón populista. Argentina: Fondo de Cultura Económica.

Lefort, C. (1988). Democracy and political theory. Great Britain: Polity Press.

Lefort, C. (1990). La invención democrática. Buenos Aires, Argentina: Nueva Visión.

Manin, B. (1998). Los principios del gobierno representativo. Madrid: Alianza Editorial

Marchart, O. (2009). El pensamiento político posfundacional. La diferencia política en Nancy, Lefort, Badiou y Laclau. Argentina: Fondo de Cultura Económica.

Mbembe, A. (2011). Necropolítica. España: Editorial Melusina.

Ojakangas, M. (2003). Carl Schmitt's Real Enemy: The Citizen of the Non exclusive Democratic Community? The European Legacy, 8 (4), 411 424. Recuperado el 18 de julio del 2009 de la base de datos EBSCO.

Pêcheux, M. (2003). El mecanismo del reconocimiento ideológico. En: Žižek, Slavoj. (comp) (2003). Ideología. Un mapa de la cuestión. Buenos Aires: Fondo de Cultura Económica

Sartori, G. (1973). What is "politics". Political Theory, 1 (1), 5-26.

Schmitt, C. (1966). Teoría del partisano. Madrid: Instituto de Estudios Políticos.

Schmitt, C. (1968). La dictadura. Madrid: Ediciones de la Revista de Occidente.

Schmitt, C. (2005). El nomos de la tierra. Argentina: Editorial Struhart \& Cía.

Schmitt, C. (2009a). El concepto de lo político. En: Schmitt, C. (2009). El concepto de lo político. España: Alianza Editorial.

Schmitt, C. (2009b). Corolario II Sobre la relación entre los conceptos de guerra y enemigo. En: Schmitt, C. (2009). El concepto de lo político. España: Alianza Editorial.

Schmitt, C. (2009c). Prólogo. En: Schmitt, C. (2009). El concepto de lo político. España: Alianza Editorial.

Serrano Gómez, E. (1998). Consenso y conflicto. Schmitt, Arendt y la definición de lo político. México: Ediciones Cepcom.

Spivak, G. (2010). Crítica de la razón poscolonial. Madrid: Ediciones Akal.

Staten, H. (1984). Wittgenstein and Derrida. Nebraska: University of Nebraska.

Strauss, L. (2008). Comentario sobre El concepto de lo político de Carl Schmitt. 
En: Meier, H. (2008). Carl Schmitt, Leo Strauss y el concepto de lo político. Buenos Aires: Katz Editores.

Villegas Contreras, A. (2003). El nuevo orden mundial y la pérdida del enemigo. Intersticios, 8 (19), 59 - 69. Recuperado el 18 de julio del 2009 de la base de datos EBSCO.

Žižek, S. (2002). Mirando al sesgo. Una introducción a Jacques Lacan a través de la cultura popular. 1 ed. 1 reimp. Buenos Aires, Argentina: Paidós.

Žižek, S. (2005). El sublime objeto de la ideología. 1 ed. 1 reimp. Buenos Aires: Siglo XXI Editores. 